\title{
Effect of Agitator's Types on the Hydrodynamic Flow in an Agitated Tank
}

\author{
Mohammed Foukrach ${ }^{1 *}$, Mohamed Bouzit ${ }^{1}$, Houari Ameur ${ }^{2}$ and Youcef Kamla ${ }^{3}$
}

\begin{abstract}
The aim of this paper is to study the effect of agitator's types on the turbulent flows in stirred tanks without and with baffles. The hydrodynamics behavior induced by four different agitator's types: a Rushton turbine (RT), a circular blade turbine (CBT), a diverging triangular blade turbine (DTBT) and converging triangular blade turbine (CTBT) are numerically predicted by solving the Navier-Stokes equations and RNG $k-\varepsilon$ turbulent model. The simulations are carried out using the Multi Reference Frame (MRF) approach. The numerical results showed good agreement with experiment. We find that the agitator CTBT gives an important profit on the power consumption per report/ratio the others and DTBT give a good reduction of the vortex size of the impeller angles.
\end{abstract}

Keywords: Mixing, Baffled tanks, Agitators, Reynolds number, Turbulent flow

\section{Introduction}

Mixing is one of the most widely used unit operations in the chemical, bio-chemical, pharmaceutical, petrochemical, and food processing. The objective of mixing is homogenization, manifesting itself in a reduction of concentration or temperature gradients or both simultaneously, within the agitated system [1]. A stirred tank unit typically consists of a rotating impeller in a vessel. Fluid motion is promoted by the transfer of energy from the impeller into the process fluid.

The agitation of liquid in these tanks is an operation more or less simple to realize, but always complex to characterize, because of the nature of the flows and the geometry of the system. Today, the majority of the operations of agitation and mixture are carried out by means of a pendulum agitator turning around a shaft, placed in a tank, generally of cylindrical form. In literature, the study of the systems of agitation started in several works relating to the characterization of the turbulent flows. As an indication, one can quote the work of Refs. [2-7].

\footnotetext{
*Correspondence: foukrach@hotmail.com

${ }^{1}$ Mechanical Faculty of Engineering, University of Sciences and Technology of Oran Mohamed Boudhief (USTO-MB), 1505 E

M'naouar, Oran, Algeria

Full list of author information is available at the end of the article
}

The agitation system consists of the agitator and the baffles, the baffles are used to break the liquid flow to increase turbulence and mixing efficiency. There are a number of comprehensive studies on baffled tanks that investigate their hydraulic efficiency [8-10].

The present work aims to determine the influence of geometrical parameter of a stirred vessel with down pumping direction from a pitched blade turbine (PBT $45^{\circ}$ ) on the hydrodynamic flow structure. The effect of the addition of a cylindrical bump in the center of dished bottom tank and the reduction of the bottom height with the same distance by realizing four geometries are also investigated. In planes $r-z$ the effect from the reduction on the bottom height for all configurations tank with bump allows good growth parameters mixture for turbulent viscosity, turbulent kinetic energy and mean velocity [11].

They study an effect of the tubular baffles configuration in an agitated vessel with a high-speed impeller on the power consumption. Aqueous solutions of $\mathrm{CMC}$ were agitated within transitional range of the non-Newtonian liquid flow in the agitated vessel of inner diameter equal to $0.6 \mathrm{~m}$. Eight different types of the impellers were tested: Rushton or Smith turbines, turbine with straight blades, pitched blade turbines and propeller. The results show that geometry of the tubular 
baffles mostly affects the power number for the system with radial flow Rushton turbine [12].

Agitating liquids in unbaffled stirred tank leads to the formation of a vortex in the region of the impeller shaft when operating in the turbulent flow regime. A numerical model is presented here that captures such a vortex. The volume of fluid model, a multiphase flow model was employed in conjunction with a multiple reference frame model and the shear stress turbulence model [13].

Power characteristics for an agitated vessel equipped with planar short baffles of length $L$ and pitched blade turbine of pitch $\beta$ are presented in the paper. The studies were carried out in the vessel of inner diameter $D=0.6 \mathrm{~m}$, where the baffles were located in the distance $p$ from the vessel bottom $(p+L=H)$. The effects of the pitch $\beta$ and geometrical parameter $p / H$ on the power number Ne were determined mathematically. The results showed that, for the assumed value of the angle $\beta$, the function $N e=f(L / H)$ decreases with the decrease in the baffle length $L$ (i.e., with the increase in the parameter $p$ ). The greatest differences between power numbers $\mathrm{Ne}$ were observed for the turbine with the flat blades $\left(\beta=90^{\circ}\right)[14]$.

They make a comparative study enters of the baffled tanks and other not baffled, these tanks equipped with a mobile with agitation of the Maxblend type. They found that the consumption of energy is higher in the tanks baffled by reports/ratios with the not baffled tanks [15]. He studies the effect of the design of the tanks on the flow models, the size of the tank and the power consumption. The three shapes of different tanks were carried out: a flat-bottomed cylindrical tank, a dished bottom cylindrical tank and a closed spherical tank. The comparison between the results obtained for the three configurations of tank showed that the spherical forms provide uniform flows in all the volume of the tank and require a less of power consumption per report/ratio the others (flat bottom and dished bottom) [16].

They studied by digitally simulates the effect of the curve of the baffles on the power number, they tested several geometrical configurations with the striping curve of baffles vary from 0 up to $7 / 30$, they showed that the baffles curved also influence the stability of the free face [17].

They studied the effect of the baffles on the consumption of energy in a tank agitated by a Rushton turbine. Three types of the tanks were used: without baffles, with baffle and a tank with slits placed at the perimeter external of its vertical wall. The effect the length of the slit was studied. The comparison between numerical results envisaged and the experimental data available shows a satisfactory agreement. They found new indicates tank which minimizes the consumption of energy [18].

They tested by a numerical study the effect of the angle of inclination of the baffles, several angles tested in this work $25^{\circ}, 32^{\circ}, 45^{\circ}, 70^{\circ}$ and $90^{\circ}$. They found that the angle of inclination of the baffles $25^{\circ}$ ensures a good mixture at a time reduced and with an energy consumption reduced to. In addition, the free face is more stable in the tanks equipped with baffles tilted $25^{\circ}$ [19].

They studied a digital simulation of the flow of the fluids pseudo-plastics in a tank mechanically agitated by a Rushton turbine. The presence of the baffles in the tank has an important influence on the vortex size. The width of these baffles must be optimized. The determination of the size of these vortices is highlighted and the influence of the theological and hydrodynamic parameters of the fluids is studied. They concluded when the baffle width is sufficient, the vortex is removed, but the consumption is then a maximum.

The power of agitation increases with the increase in the structural index, because of the viscous forces, and it varies slightly starting from the transitory mode [20]. The technique of particle image velocimetry is used to analyze the vortices of wake and to elucidate their relationship to the properties of turbulence in a tank agitated by four various agitators, Rushton turbine; turbine with a disc with blades: concave, semi elliptic, parabolic [21]. The results showed that more the curve is broad plus the vortex resides longer at the blade tip, a longer distance between the higher and lower vortex, one longer life span and leads to the formation of smaller and more robust vortices.

The turbulent kinetic energy decreases more the curve is large, because of the progressive reduction in the power provided for the same Reynolds number; the area of larger, dissipated power $\varepsilon$ and turbulent kinetic energy $\kappa$ is the zone between the higher and lower vortex; as well as the difference in distribution of $\kappa$ and $\varepsilon$ of the four turbines is associated with different axes from the vortex of wake due to the shape of the blades.

In the present work, single-phase flow patterns in a stirred vessel have been investigated using (CFX 16.0) in a turbulent flow regime using four different agitator's types, a Rushton turbine (RT), a circular blade turbine (CBT), a diverging triangular blade turbine (DTBT) and converging triangular blade turbine (CTBT). Comparisons have been made of the flow fields produced when the impellers are operated in the down- and up-pumping modes. These velocity fields have been assessed by examining the power consumption and vortex sizes.

Hence, the objective of this work is to: 
- Analyze and determine the effect of the agitator's types on the hydrodynamic flow structure.

- Reduce the power consumption and vortex size.

- Our attention is focused on the effect: baffle height rotation, impeller angle, circular horizontal cut baffle and impeller clearance ratio.

\section{Description of the Stirred System}

The geometry consisted of a flat-based fully baffled cylindrical vessel filled with fluid to a height, $H$, equal to the diameter $D$. The diameter of cylindrical vessel $D=0.6 \mathrm{~m}$, the diameter of rotating shaft $d_{\mathrm{sh}}=d / 5$. The four metallic baffles were $D / 10$ in width and about $D / 200$ in thickness, vertical and close to the wall. The stirrers used were four different types of agitators with six blades, fixed on a disc: Rushton Turbine (RT), Circular Blades Turbine (CBT), Diverging Triangular Blades Turbine (DTBT) and Converging Triangular Blades Turbine (CTBT), with the same volume, positioned at a clearance $c=D / 3$ from the bottom of the tank (Figure 1). The dimensions of the four agitators are presented in Table 1.

\section{Theoretical Backgrounds}

The working fluid is pure water at room temperature $20^{\circ} \mathrm{C}$ with density $\rho=997 \mathrm{~kg} / \mathrm{m}^{3}$ and viscosity $\mu=0.89 \times 10^{-3}$ Pa.s. They are the same as the experimental study of Ref. [22].

The manner most used to characterize an agitated system is the determination of the dimensionless numbers. These characteristic parameters can be expressed starting from the fundamental units (mass, length, time). The Reynolds number $(R e)$ provides information on the relation between the inertias and the forces viscous acting on a fluid. This value indicates if the fluid has a laminar behavior $(\operatorname{Re}<20)$ or turbulent $\left(\operatorname{Re}>10^{4}\right)$.

The Reynolds number of the flow in a stirred vessel is defined as:

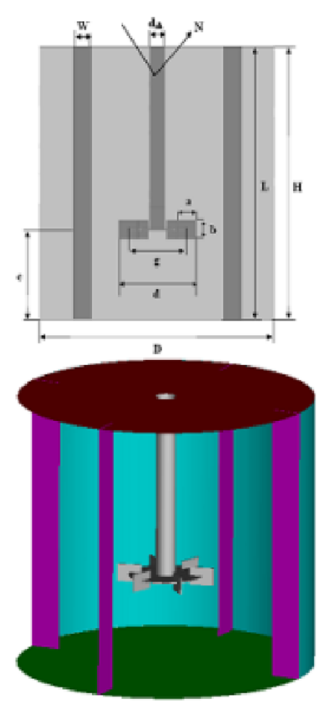

RT

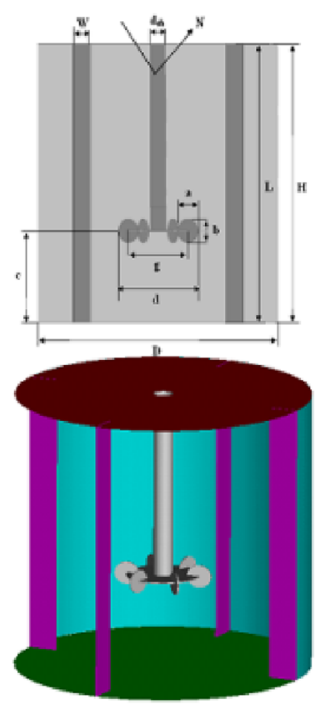

CBT

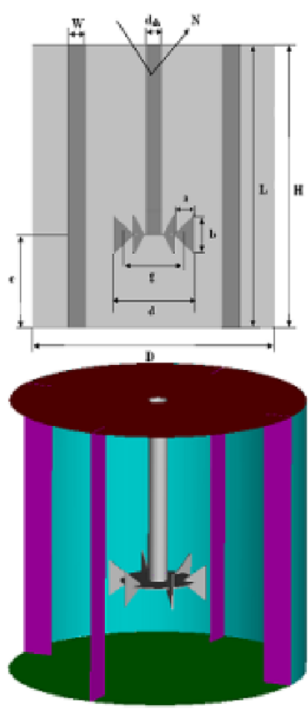

DTBT

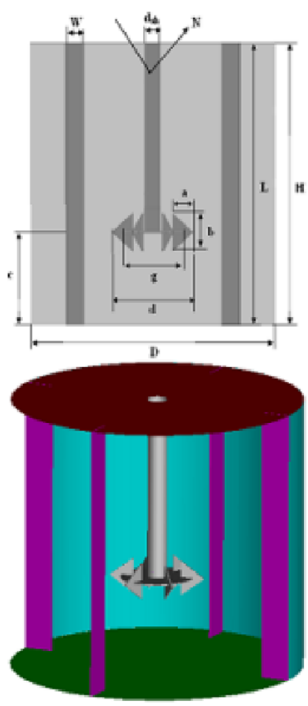

CTBT

Figure 1 Stirred vessel configurations

Table 1 Impellers geometrical proprieties

\begin{tabular}{lllll}
\hline Agitators & $\begin{array}{l}\text { Impeller diameter } \\
\boldsymbol{d}(\mathbf{m m})\end{array}$ & $\begin{array}{l}\text { Blades length } \\
\boldsymbol{a}(\mathbf{m m})\end{array}$ & $\begin{array}{l}\text { Blades width } \\
\boldsymbol{b}(\mathbf{m m})\end{array}$ & $\begin{array}{l}\text { Disc diameter } \\
\boldsymbol{g}(\mathbf{m m})\end{array}$ \\
\hline RT & 198 & 49.5 & 39.6 & $\begin{array}{l}\text { Shaft diameter } \\
\boldsymbol{d}_{\mathbf{s h}}(\mathbf{m m})\end{array}$ \\
CBT & 198.45 & 49.81 & 49.81 & 39.6 \\
DTBT & 198 & 49.5 & 79.2 & 39.5 \\
CTBT & 198 & 49.5 & 79.2 & 39.6 \\
\hline
\end{tabular}




$$
R e=\frac{\rho N D^{2}}{\mu}
$$

where $\rho$ is the density, $N$ is the number of impeller revolutions $(\omega=2 \pi N, \omega$ is the angular velocity), $\mu$ is the dynamic viscosity of the working fluid.

The radial $(R)$ and axis $(Z)$ coordinates are normalized as:

$$
R^{*}=2 R / Z, Z^{*}=Z / D \text {. }
$$

The tangential, radial and axial velocities are normalized with the blade tip velocity:

$$
V_{\theta}^{*}=V_{\theta} / V_{t i p}, V_{r}^{*}=V_{r} / V_{t i p}, V_{z}^{*}=V_{z} / V_{t i p}, V_{t i p}=\pi N D .
$$

In a dimensionless form, the power number is defined by:

$$
N_{P}=\frac{P}{\rho N^{3} D^{5}} .
$$

The power consumption $(P)$ depends on all the parameters characterizing the external geometry of the vessel, the stirrer geometry, flow regime and the rotating speed of the impeller. The power is calculated according to a determination of the couple necessary to make turn the agitator, by the use of an assembly of dynamometer making it possible to measure the cable which is exerted on the shaft actuating the agitator.

The losses with the frictions on the parts moving are evaluated with the no-load tests in which agitation turns in the air.

The consumption is obtained by the equation:

$$
P=2 \pi\left(C-C_{0}\right),
$$

where $C$ the couple in load and $C_{0}$ the couple in vacuum.

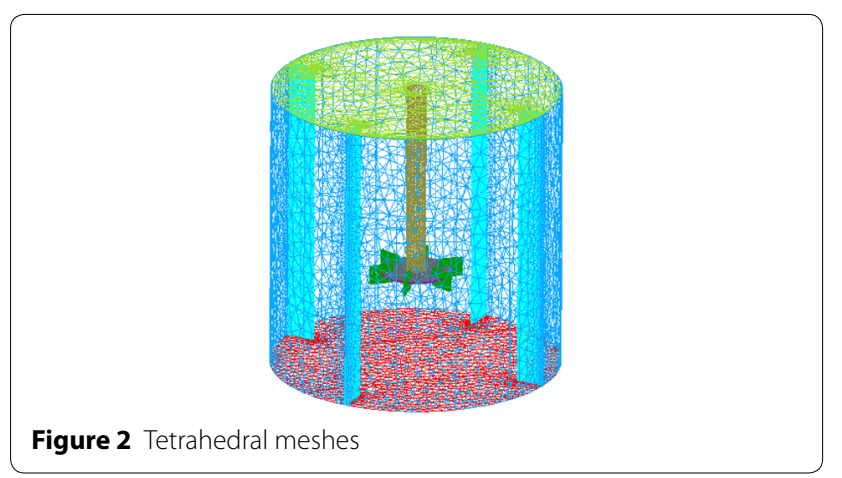

\section{Numerical Details}

In this study, the commercial software CFX 16.0 was used to simulate 3D flow fields in stirred vessels equipped with a four agitator's type (RT, CBT, DTBT and CTBT). The geometry was created and meshed the computational domain by tetrahedral cells (Figure 2). The computational grids were defined by unstructured, non-uniformly. Numerical test were carried out to confirm the effect of mesh size on the calculated results. Table 2 shows a total grid of 501312 was enough to get mesh independence resolution.

In unbaffled tanks, the stirrer rotation was modeled by using the Rotating Reference Frame (RRF) method. Here, the impeller is kept stationary and the flow is steady relative to the rotating frame, while the outer wall of the vessel is given an angular velocity equal and opposite to the velocity of the rotating frame. This approach can be employed due to the absence of baffles [23].

The Multiple Reference Frame (MRF) approach was used in baffled tanks; this technique consists of dividing the computational domain into two parts: an inner rotating cylindrical volume enclosing the turbine and an outer stationary volume containing the rest of the tank. Other details of this technique are found in Ref. [18]. Several studies have focused on the MRF approach like Refs. [24-27].

The multiple reference frames (MRF) method is the most suitable method to simulate impeller rotation in mixing systems. Precise determination of stationary and moving zones in MRF method leads to accurate results in mixing performance [28].

In this study, the Reynolds number is varying from $10^{4}$ to $10^{5}$. The RANS, RNG $k-\varepsilon$ model used for modeling the turbulent flow in the agitated tanks and gives a good result; we can quote some work on this model by Refs. [29-32]. The effect of the modeling approach, discretization scheme and turbulence model on mean velocities, turbulent kinetic energy and global quantities, such as the power and circulation numbers, has been investigated.

The type of the turbulence model was limited to the $\kappa-\varepsilon$ and RNG models due to convergence difficulties encountered with a Reynolds Stress Model (RSM) and there was found to be little effect of these models on the mean flow and turbulent kinetic energy [7]. They studied

Table 2 Comparison of power number between simulation with different grid number and experimental of baffled tank (at $R e=10^{5}$ )

\begin{tabular}{lllll}
\hline \multicolumn{3}{c}{ Simulation } & Experimental \\
\hline Grid number & 210680 & 376680 & 501312 & \\
Power number & 5.221 & 5.432 & 6.0 & 6.0 \\
\hline
\end{tabular}


the effect of three models of turbulence $(\kappa-\varepsilon$, RNG and RSM) in a stirred tank by using an MRF approach on the tangential velocity field. They found that the RNG model reduced the unphysical reverse swirl region in the upper tank predicted by simulations [33].

The mathematical modeling and numerical simulation of the turbulent, two-phase flow of liquid and gas in a gas induced agitated stirred- tank reactor using computational fluid dynamics (CFD) techniques. A threedimensional (3D), transient, Euler-Euler two-phase flow model is developed and used to investigate the turbulent flow and mixing of liquid and bubbles in the stirred-tank reactor, applying the sliding mesh approach. Turbulence is simulated by means of several available models, the Renormalization Group (RNG) $\kappa-\varepsilon$ model being the one finally recommended as the most appropriate of the ones studied, for the present application [34]. The re-normalization group (RNG) $\kappa-\varepsilon$ model, large eddy simulation (LES) model and detached eddy simulation (DES) model were evaluated for simulating the flow field in the stirred tank.

All turbulence models can reproduce the tangential velocity in an unbaffled stirred tank with a rotational speed of $150 \mathrm{r} / \mathrm{min}, 250 \mathrm{r} / \mathrm{min}$ and $400 \mathrm{r} / \mathrm{min}$, respectively. LES model and RNG $\kappa-\varepsilon$ model predict the better tangential velocity and axial velocity, respectively [35]. Simulations was converted when normalized residuals for pressure and velocities drop below $10^{-5}$. Most calculations required 1700-2000 iterations and about 8-10 h.

\section{Results and Discussion}

In practice, the flow in the stirred tanks is three-dimensional. However, the absence of baffles does not ensure a good quality of mixing, this is due to the fact that the flow is mainly tangential, on the other hand the mixing becomes more efficient if the steering system comprises baffles, and that this translated by the transformation of the predominantly tangential flow into a three-dimensional flow. The different configurations of the agitator types (RT, CBT, DTBT, and CTBT) are shown in Figure 3 for tanks without baffles.

In order to verify the reliability of the calculation code and the simulation method used, reference was made to the work of Ref. [22]. Note that the same geometric conditions as those undertaken as well as the same fluid, were simulated. The numerical predicted results for the power consumed in a cylindrical vessel without baffles on the left and with baffles on the right (Figure 4) and were compared with those of Karcz and Major [22]: a satisfactory agreement was noticed.

Figure 5 illustrates the power number $N_{P}$ in a cylindrical vessel without baffles provided with different agitator's types (RT, CBT, DTBT, CTBT) according to the Reynolds number $R e$ which varies between $10^{4}$ and $2 \times 10^{5}$. From the graph, it can be noted that the tanks which have agitators: DTBT and CTBT are identical with a mean power number about 2.5 and the others (RT and CBT) $N_{P}$ about 1.

When the stagnant areas exist in a stirred tank, mass transfer and heat is lower with higher temperature gradients, which makes it is necessary to eliminate these undesirable regions in the tank [36]. The effect of certain parameters on the flow fields is presented.

Figure 6 illustrates the different flow structures obtained for the four agitator's types (RT, CBT, DTBT, CTBT) with Reynolds number $R e=4 \times 10^{4}$. It can be seen that the intensity of the speed is higher at the end of the blades (RT, CBT, and DTBT) and less intense for the CTBT agitator as well as a large swept area up and down the blades for RT and DTBT and low area scanned for the CTBT. These types of turbine split the flow into two streams: one going towards the bottom of the tank and the other towards the free liquid surface, resulting thus is the formation of two vortices above and below the turbine.

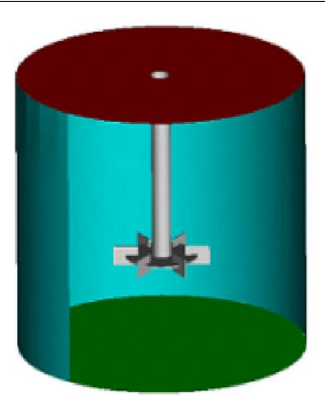

RT

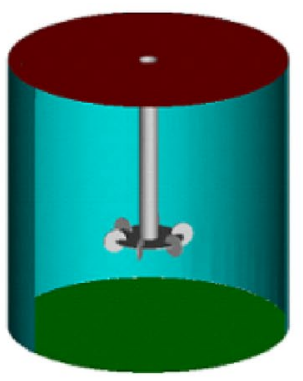

CBT

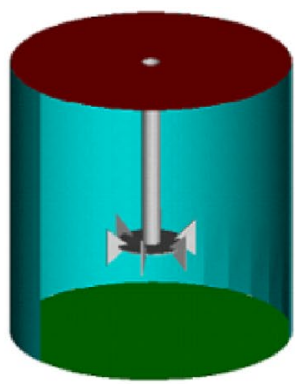

DTBT

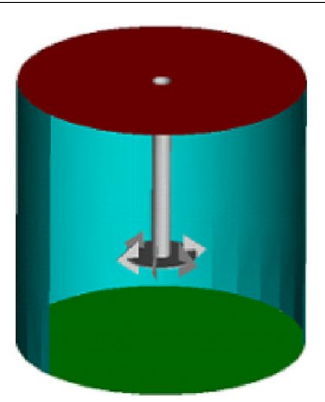

CTBT

Figure 3 Stirred vessel configurations without baffles 

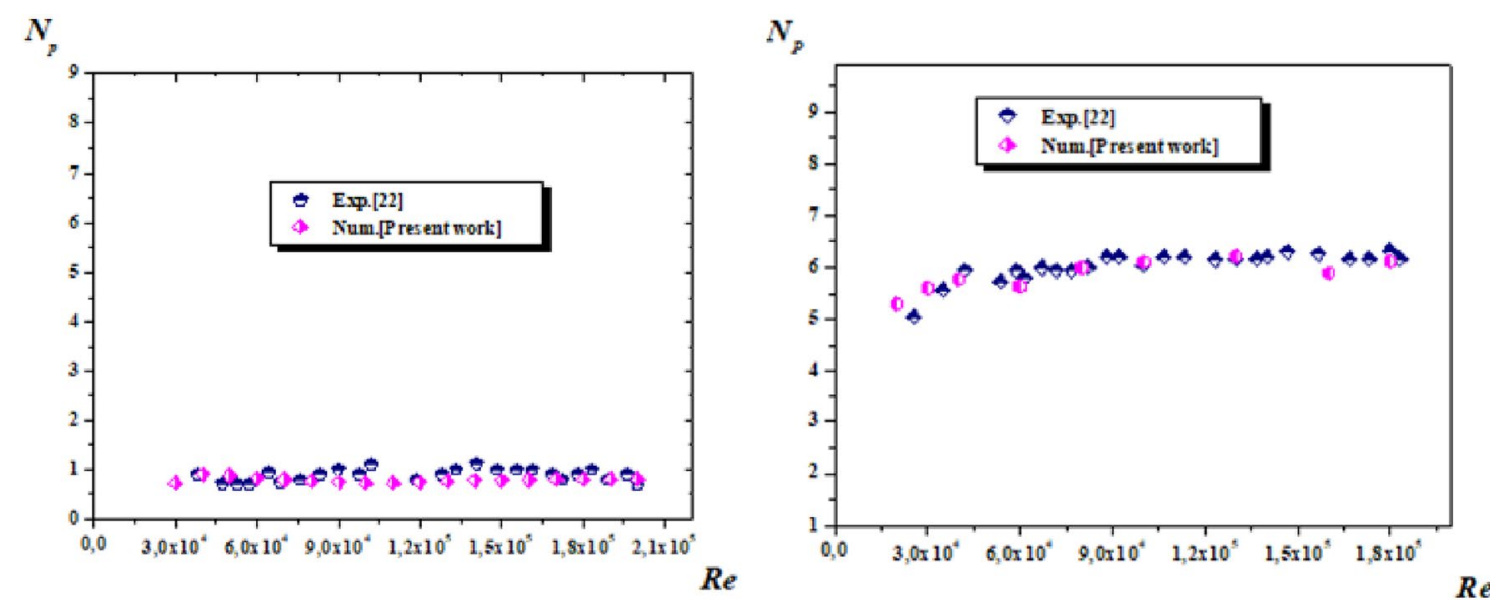

Figure 4 Power number vs. Reynolds number in unbaffled (in left) and baffled vessel (in right) (validation)

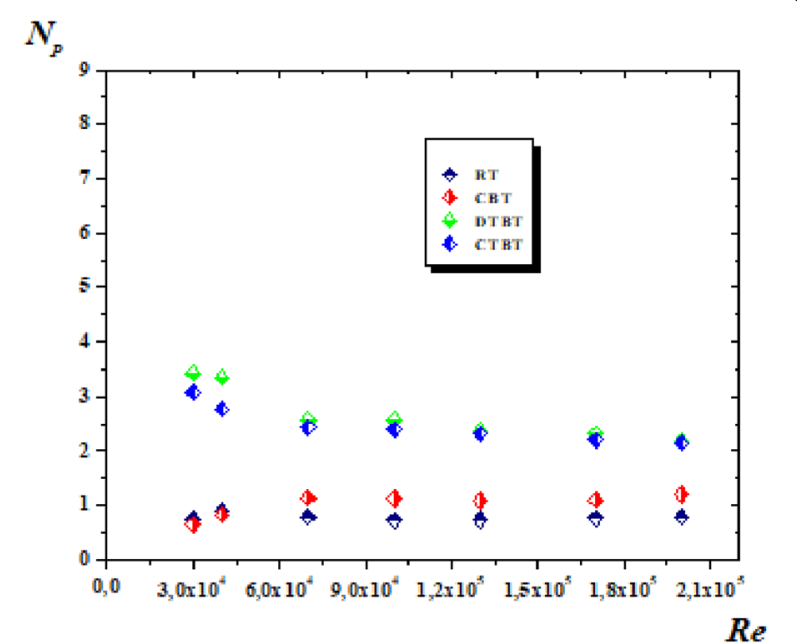

Figure 5 Power number for different agitator's types of unbaffled tanks

Figure 7 illustrates axial speeds of the agitated tanks with vertical baffles of different agitator's types (RT, CBT, DTBT, CTBT) with Reynolds number $R e=4 \times 10^{4}$, $R^{*}=0.18$ and $Z^{*}=0.183$. In the figure on the left the axial speed with length for the height of the tank, we can notice that agitators (RT and CTBT) are identical; an important value axial speed in agitator DTBT varies approximately 0.035 and low value axial speed in agitator CBT.

On the right the axial speed with a length of the radius of the tank, axial speeds of the four agitators remain almost constant for $R^{*}$ varies between 0.05 and 0.25 then to increase for reaching a maximum value for agitator DTBT vary approximately 0.025 .
The vortex size of the four agitator's types (RT, CBT, DTBT, and CTBT) is presented in Figure 8 according to the values of Reynolds number $R e$ varies from $10^{4}$ to $10^{5}$. We can notice a maximum value of the vortex size approximately 0.655 of two agitators (DTBT and CTBT) with $R e=104$ then a major reduction varies approximately 0.4 of two agitators (RT and CBT) for $R e=4 \times 10^{4}$ then to increase until reaching a value of 0.55 for DTBT with $R e=10^{5}$.

The power consumption is a global parameter to describe the performance of a mechanically agitated system. Table 3 shows the variation of the power number $N_{P}$ with Reynolds number $R e=4 \times 10^{4}$ in a tank with baffles and the other without baffles with four agitator's types: RT, CBT, DTBT, CTBT and we compared our numerical results with the experimental ones of Ref. [18]; one obtains a good value with the experimental one for the agitator RT and a decrease for the others in the baffled tanks and an increase of the NP for the unbaffled tanks (CTB, DTBT, CTBT), it is noted that the CTBT stirrer reduces the power consumption about $43.83 \%$ in the baffled tank.

\subsection{Effect of Baffle Height Ration $(L / H)$}

Experimentally, they studied the effect of baffle height for different agitator's types (Rushton turbine, propeller, radial blade turbine, flat and inclined) on the turbulent energy consumption [22]. They found than the Rushton turbine type characterized by higher energy consumption by comparing to the different mobiles studied.

In this section, the effect of the baffle height is studied. For this task, four Geometric configurations are realized, which are: $L / H=0.83,0.67,0.5$ and 0.33 for the cylindrical tanks with RT, CTB, DTBT and CTBT, respectively. 

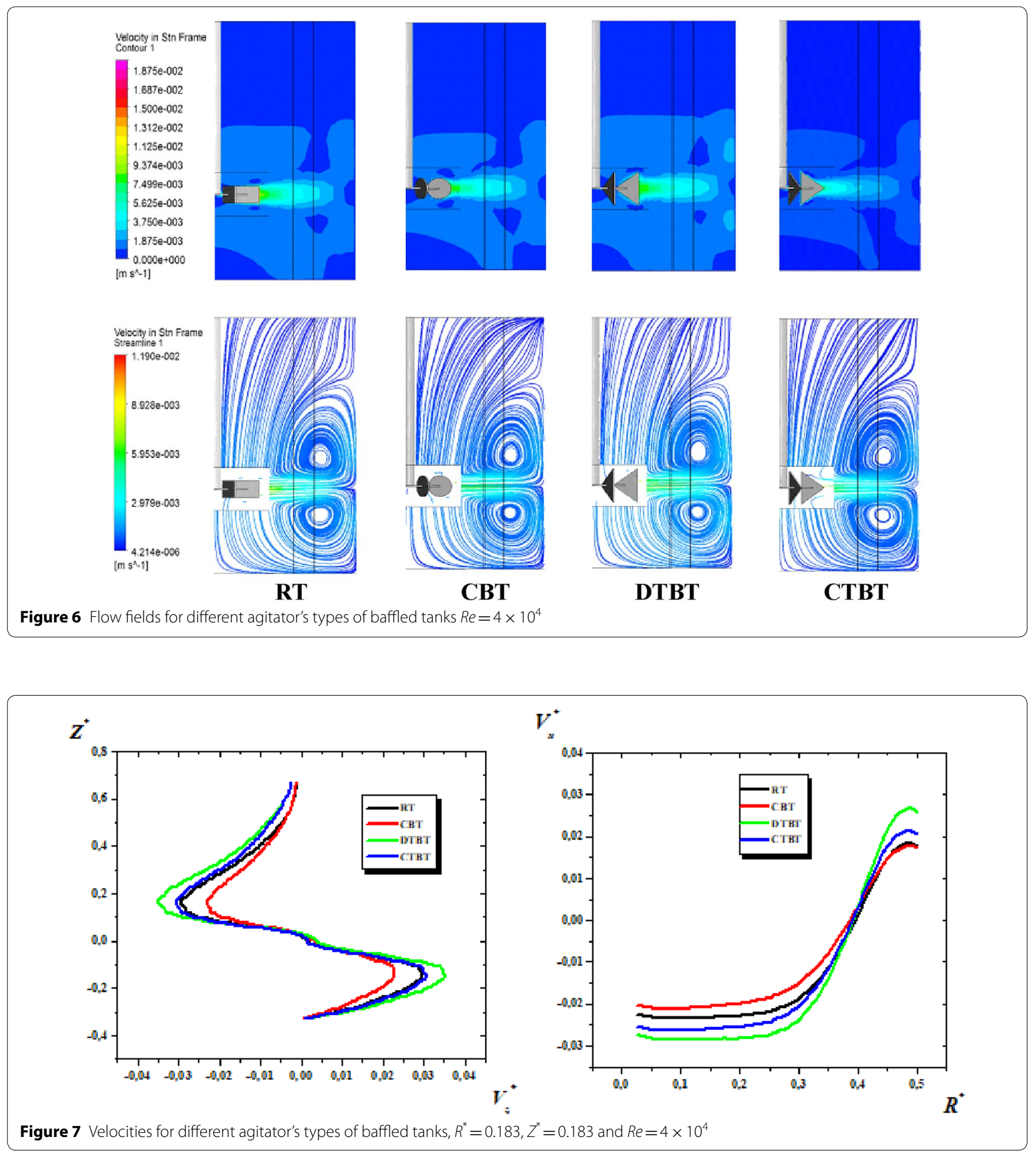

Figures 9, 10, 11 and 12 show the streamlines of the tanks with vertical baffles provided by four agitator's types with four cases of the baffle height, which are: $L / H=0.83,0.67,0.5$ and 0.33 with a Reynolds number $R e=4 \times 10^{4}$. We note that the upper vortex size for each similar remainder and we also observe that the baffle height increases vortex size decreases $(L / H=0.83$ and $0.67)$, a significant increase in the size vortex for heights $(L / H=0.5$ and 0.33$)$ due to damage to the agitator.

The axial speed profiles for different agitator's types with various baffles heights along the vessel radius, at $R^{*}=0.233$ and $R e=4 \times 10^{4}$ are schematized in 


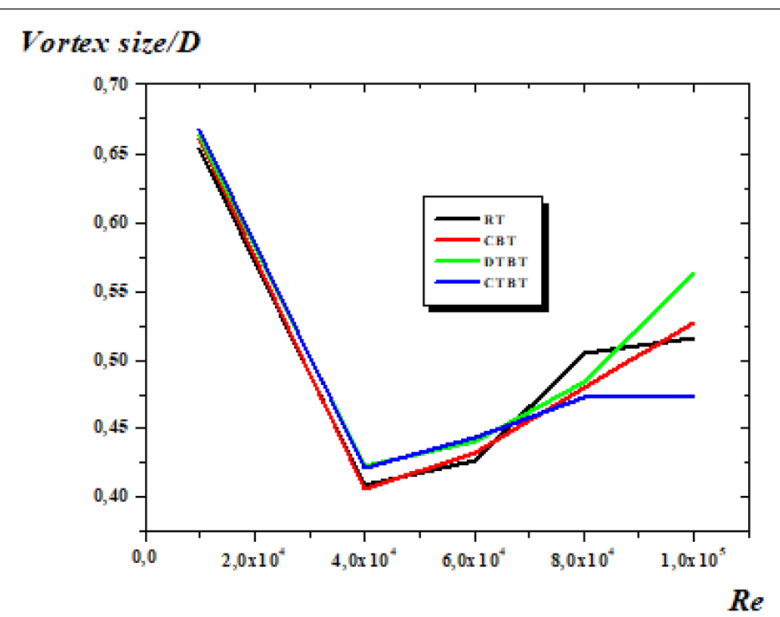

Figure 8 Vortex size depending on Reynolds number of different agitator's types in baffled tanks

Table 3 Power number of different agitator's types of tanks with and without baffles

\begin{tabular}{llllll}
\hline Agitators & RT & CBT & DTBT & CTBT & $\begin{array}{l}\text { Exp. } \\
\text { of Ref. } \\
{[\mathbf{1 8}]}\end{array}$ \\
\hline Baffled tank & 6.0 & 4.24 & 5.15 & 2.63 & 6.0 \\
Unbaffled tank & 0.79 & 1.12 & 2.57 & 2.39 & 0.82 \\
\hline
\end{tabular}

a dimensional form to show clearly the vortex size (Figure 13).

The graphs of two agitators (RT and CTBT) are identical and the size of the zone of recirculation increases continuously, one finds a maximum value of axial speed for $L / H=0.67$ approximately 0.15 and 0.13 in the top and bottom of the turbine for agitator DTBT and low value for agitator CBT approximately 0.03 in the top and bottom of the turbine and a light value axial speed in the free face of the liquid for the four reports/ratio $L / H$.

A comparison was present in Figure 14 of the variation of the power number $N_{P}$, according to the baffle height $(L / H=0.83,0.67,0.5$ and 0.33$)$ of four agitator's types (RT, CTB, DTBT and CTBT), the $N_{P}$ values almost constant for agitators (DTBT, CBT and RT) with $(L / H=0.33$, 0.5 and 0.67$)$ then increases slightly, one can also see, an important value of power number $\left(N_{P}=0.455\right)$ with the height of the baffle $(L / H=0.83)$ for agitator DTBT. An important reduction of the power consumption for CTBT with an $N_{P}$ median value approximately 2.5 .

The vortex size against the baffle height is presented in Figure 15, one can observe that the vortex size reaches a maximum value of 0.655 for $\mathrm{CBT}$ and DTBT with $L / H=0.33$ then decreases with the other heights $(L / H=0.83,0.67$ and 0.5$)$ up to a minimal value of 0.4 for CBT with $L / H=0.83$. We can deduce that a reduction of the vortex size of agitators CBT, DTBT and CTBT reduced by comparison to $\mathrm{RT}$ with the increase baffle height.

\subsection{Effect of Impeller Angle ( $\theta$ )}

In this part we interested to study the effects of the impeller angle of four agitator's types (RT, CTB, DTBT and CTBT) on the hydrodynamic flow in tanks with vertical baffles, five angles are tested $\left(\theta=10^{\circ}, 25^{\circ}, 45^{\circ}, 60^{\circ}\right.$ and $\left.90^{\circ}\right)$ with Reynolds number $R e=4 \times 10^{4}$.

Figure 16 shows vectors speed for baffled tanks with four agitator's types and various angles $\theta$, by comparison, we can notice that the intensity of the vectors raised around the turbine for two agitators (CBT and DTBT) east decreases when moves away because of the baffles which play a role of obstacle which slows down the fluid and formation of the dead zones of recirculation

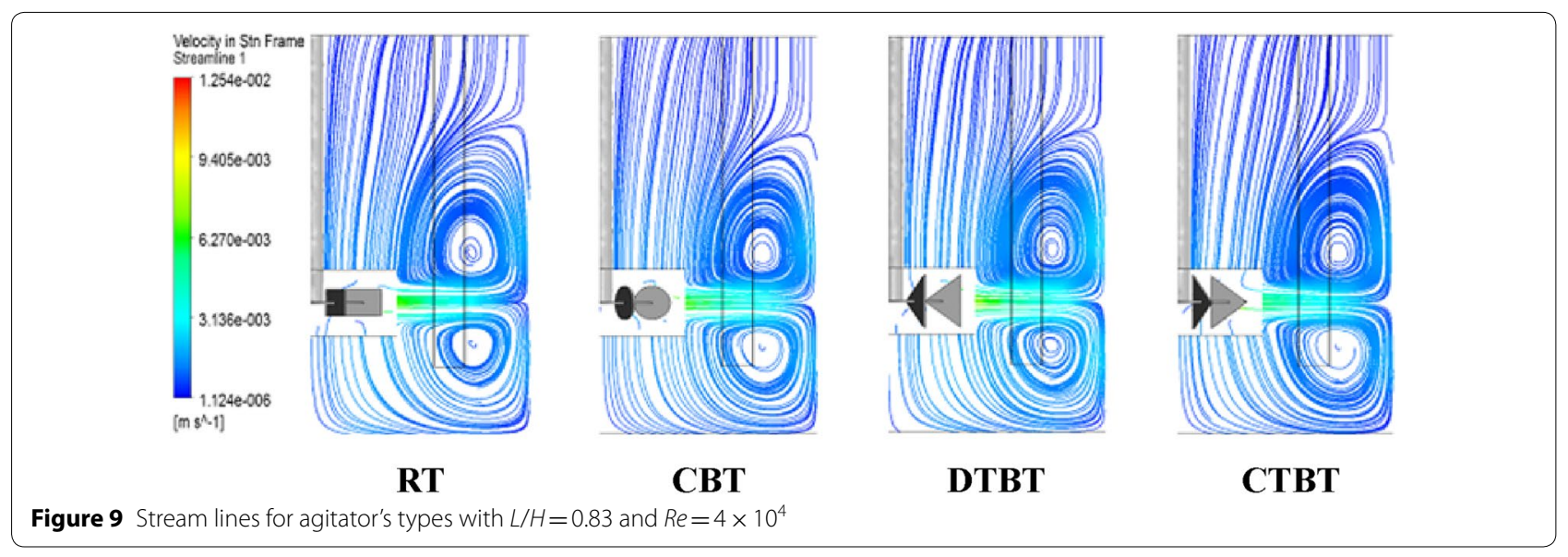



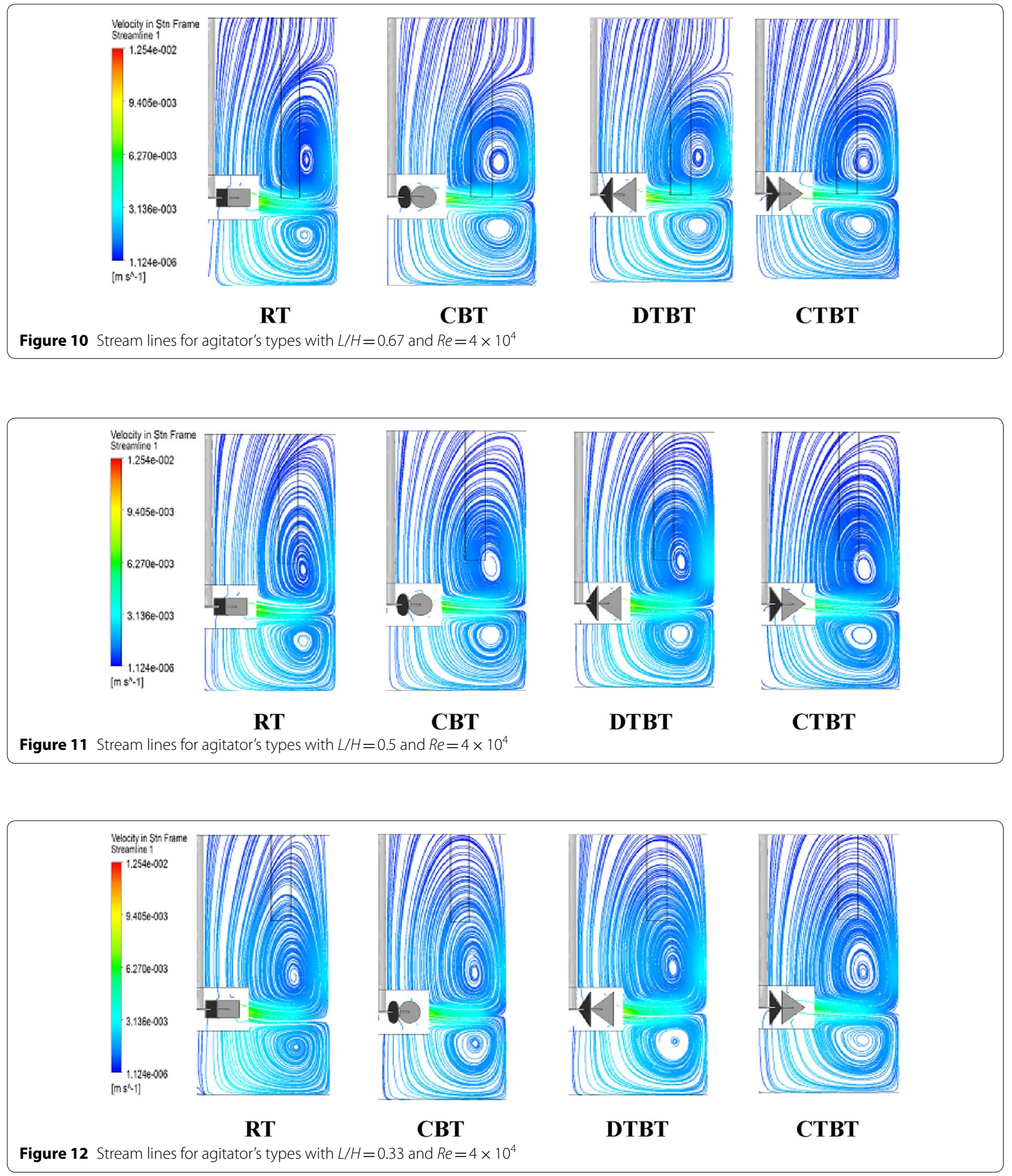


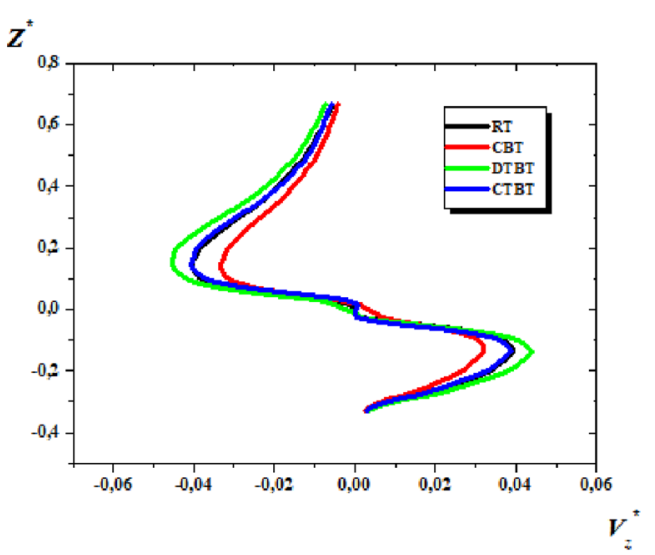

$\mathbf{L} / \mathbf{H}=\mathbf{0 . 8 3}$

$\boldsymbol{Z}^{*}$

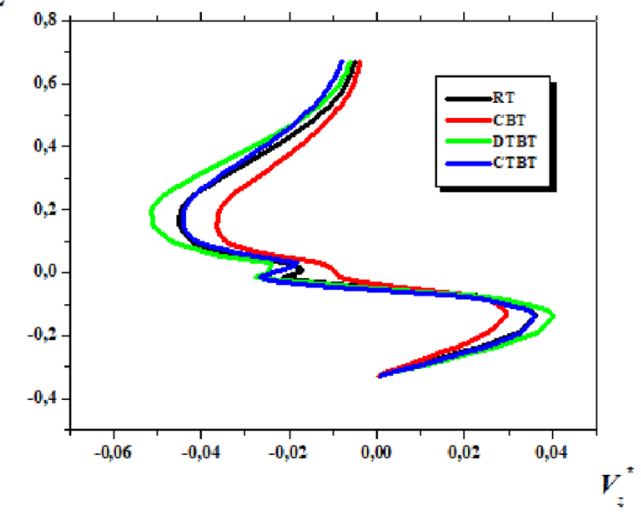

$\mathbf{L} / \mathbf{H}=\mathbf{0 . 5}$
$Z^{*}$

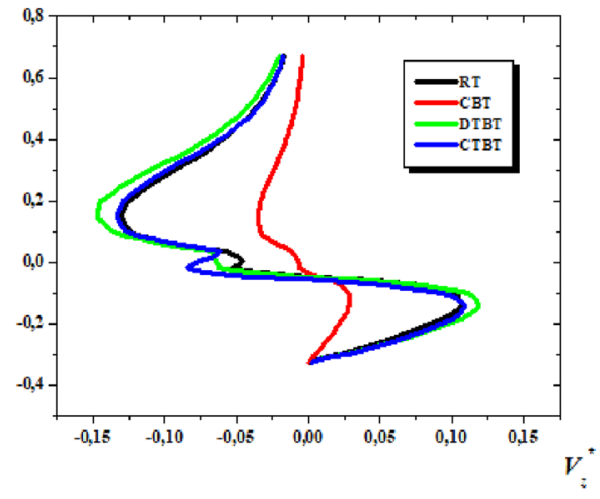

$\mathbf{L} / \mathbf{H}=\mathbf{0 . 6 7}$

$Z^{*}$

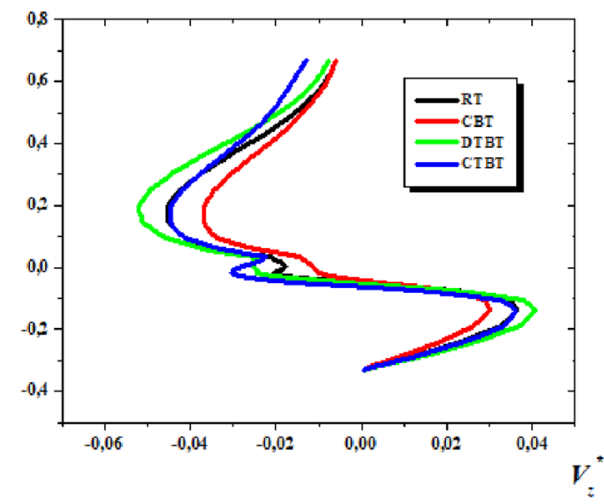

$\mathbf{L} / \mathbf{H}=\mathbf{0 . 3 3}$

Figure 13 Axial velocities for different agitator's types with various baffles heights along the vessel radius, at $R^{*}=0.233$ and $R e=4 \times 10^{4}$

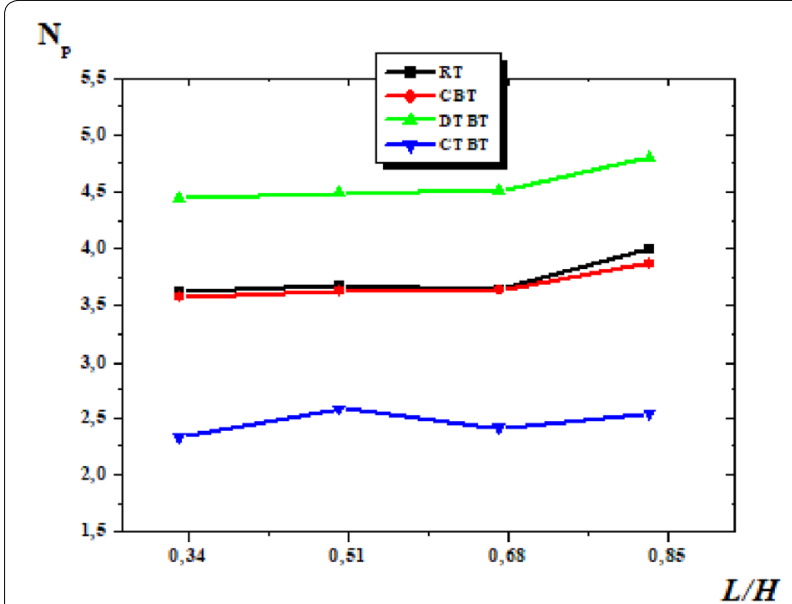

Figure 14 Power number for different agitator's types with various baffles heights, $R e=4 \times 10^{4}$

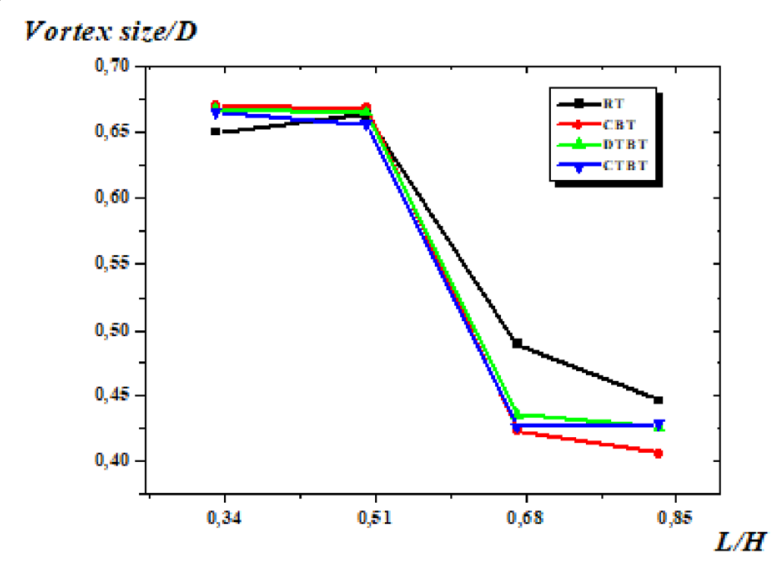

Figure 15 Vortex size for different agitator's types with various baffles heights, $R e=4 \times 10^{4}$ 


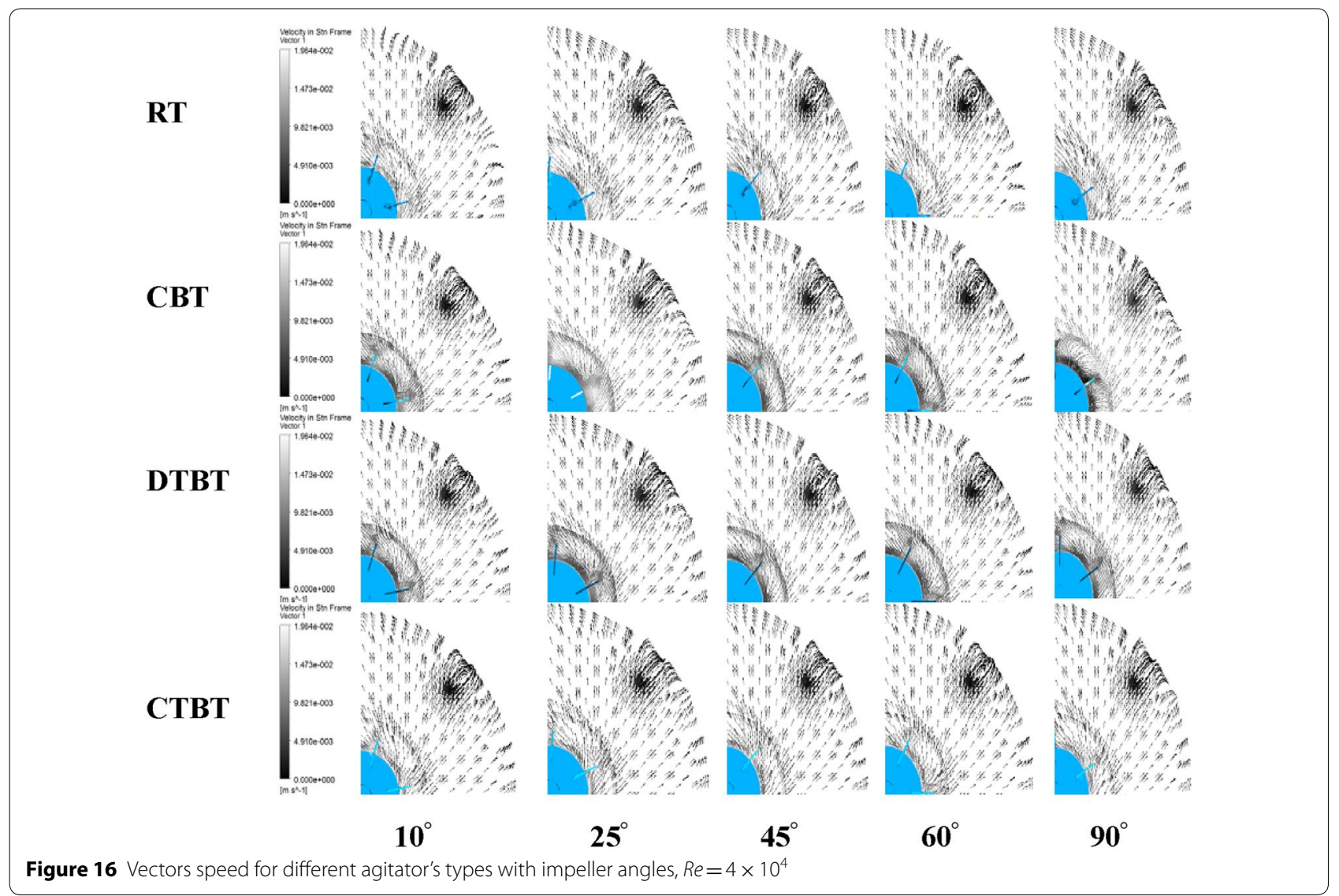

(stagnant) behind the baffles. The angles $\theta=25^{\circ}$ and $90^{\circ}$ for CBT and DTBT give a better distribution of vectors.

The five impeller angles $\left(\theta=10^{\circ}, 25^{\circ}, 45^{\circ}, 60^{\circ}\right.$ and $\left.90^{\circ}\right)$ for baffled tanks with four agitator's types with Reynolds number $R e=4 \times 10^{4}$ are studied and drawing the graphs of axial velocities along the vessel radius, at $R^{*}=0.333$ as shows in Figure 17. By comparison, between the four graphs, one notes that axial speeds almost identical for the various angles $\theta$ of the four agitator's types, one observes a maximum value axial speed approximately 0.035 in the high part of the turbine and almost 0.033 in the lower part of the turbine for agitator DTBT and minimal value for the agitator CTBT about 0.02 and 0.018 tops and low of the turbine for impeller angles $\left(\theta=25^{\circ}\right.$ and $90^{\circ}$ ) and null in the free face of the liquid.

Figure 18 illustrates the vortex size for different agitator's types with various impeller angles with Reynolds number $R e=4 \times 10^{4}$, we can note that the values of vortex size varied with the impeller angles $\theta$. A maximum value of the vortex size is about 0.66 and minimal approximately 0.4 of CTB. The agitator DTBT give a good reduction of the vortex size of the impeller angles by report/ratio the other agitators.
The power number according to the impeller angles of the tanks equipped with four agitator's types is found in Figure 19. We can note that all the graphs constant with all the angles and one observes an important power number value $N_{P}$ approximately of 5.2 of the two agitators (RT and DTBT) who are identical and a minimal value $N_{P}=2.7$ for agitator CTBT, therefore, this agitator reduces the power consumption almost half.

\subsection{Effect of Circular Horizontal Cut Baffle (CHCB)}

They find that the cylindrical vessel with cut horizontal circular baffle (CHCB) at an angle of $20^{\circ}$ decreases the size of the vortex and reduces power consumption by comparing a cylindrical vessel with four designs ( $\mathrm{CHCB})$ is a better design to avoid damage to the agitator [37].

Four configurations have been realized to study the influence of the cut circular horizontal baffle $(\mathrm{CHCB})$ with an angle of $20^{\circ}$ in cylindrical tanks with RT, CTB, DTBT and CTBT as shown in Figure 20.

Figure 21 allows to compare the effect of $\mathrm{CHCB}$ with an angle of $20^{\circ}$ and Reynolds number $R e=4 \times 10^{4}$ on the cavernous size of the flow (zone of intense motion forms around the stirrer) for tanks containing $\mathrm{RT}, \mathrm{CBT}$ and 
$Z^{+}$

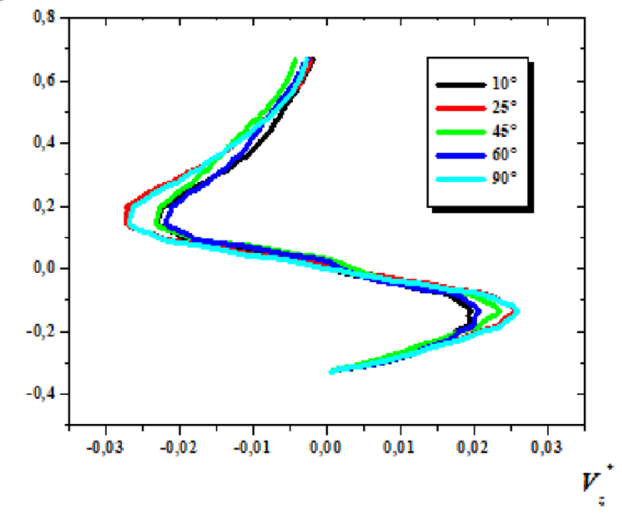

RT

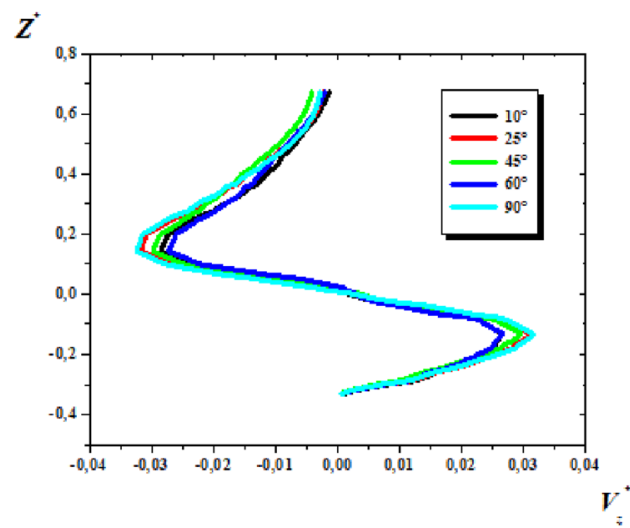

DTBT
$Z^{+}$

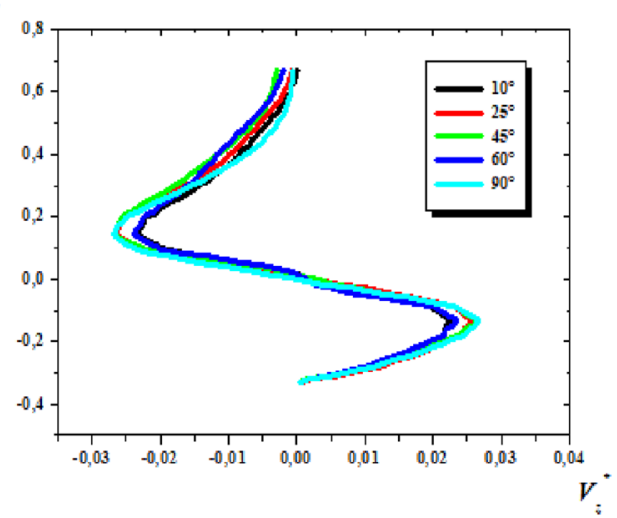

CBT

$Z^{*}$

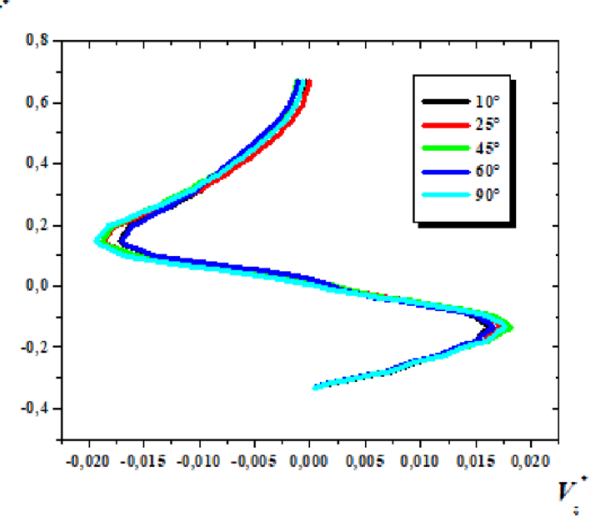

CTBT

Figure 17 Axial velocities for different agitator's types with various impeller angles along the vessel radius, at $R^{*}=0.333$ and $R e=4 \times 10^{4}$

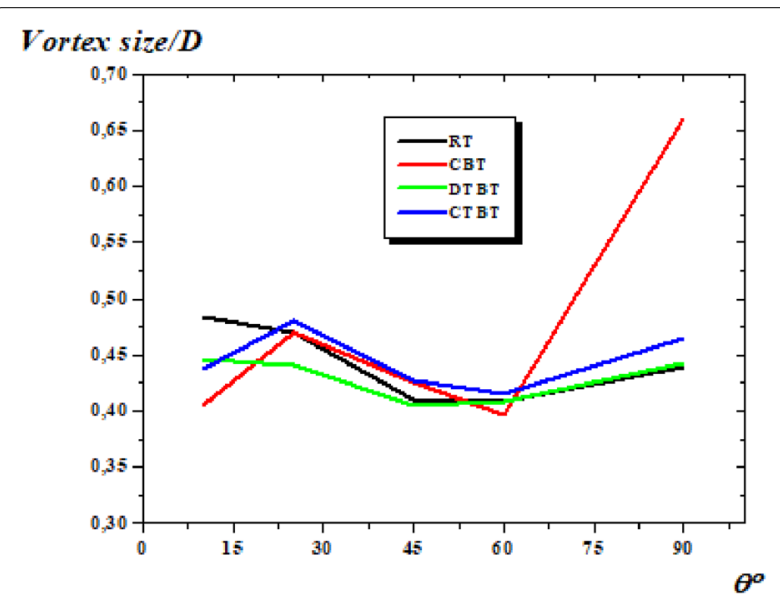

Figure 18 Vortex size for different agitator's types with various impeller angles, $R e=4 \times 10^{4}$

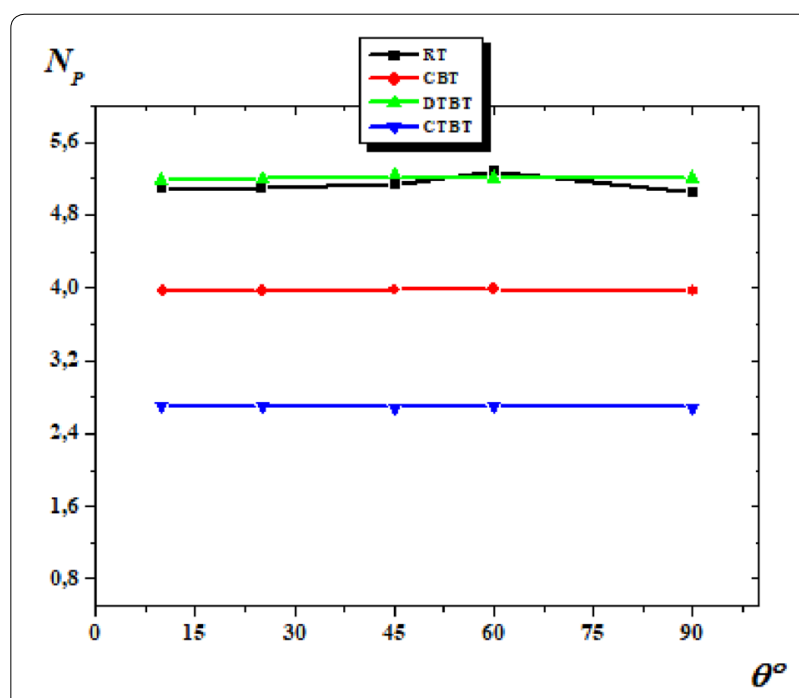

Figure 19 Power number versus impeller angles for different agitator's types, $R e=4 \times 10^{4}$ 


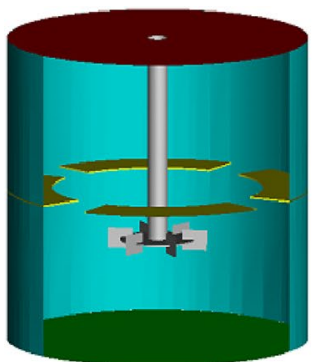

RT

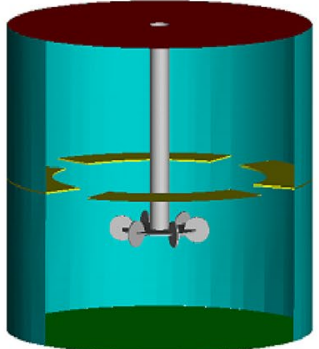

CBT

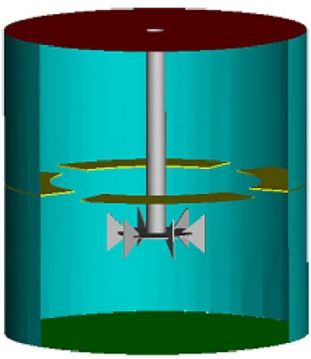

DTBT

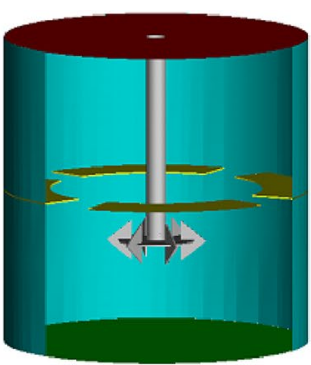

CTBT

Figure 20 Stirred vessel configurations with CHCB for an angle $20^{\circ}$
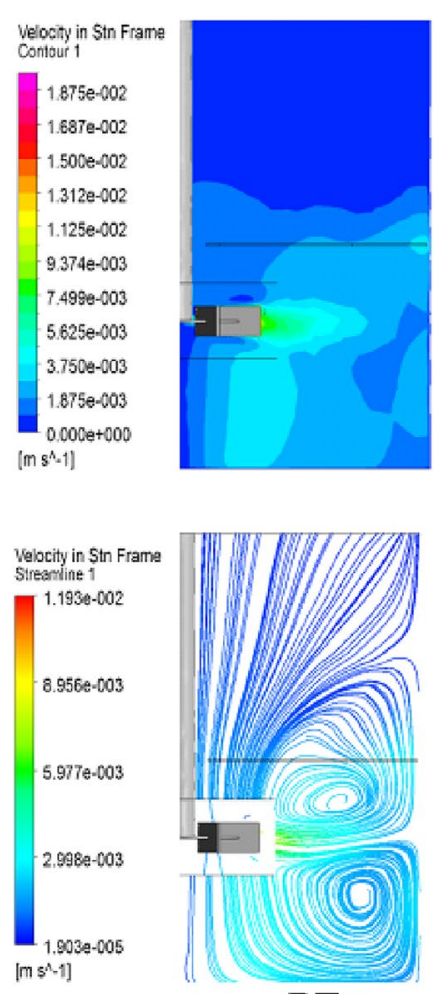

RT
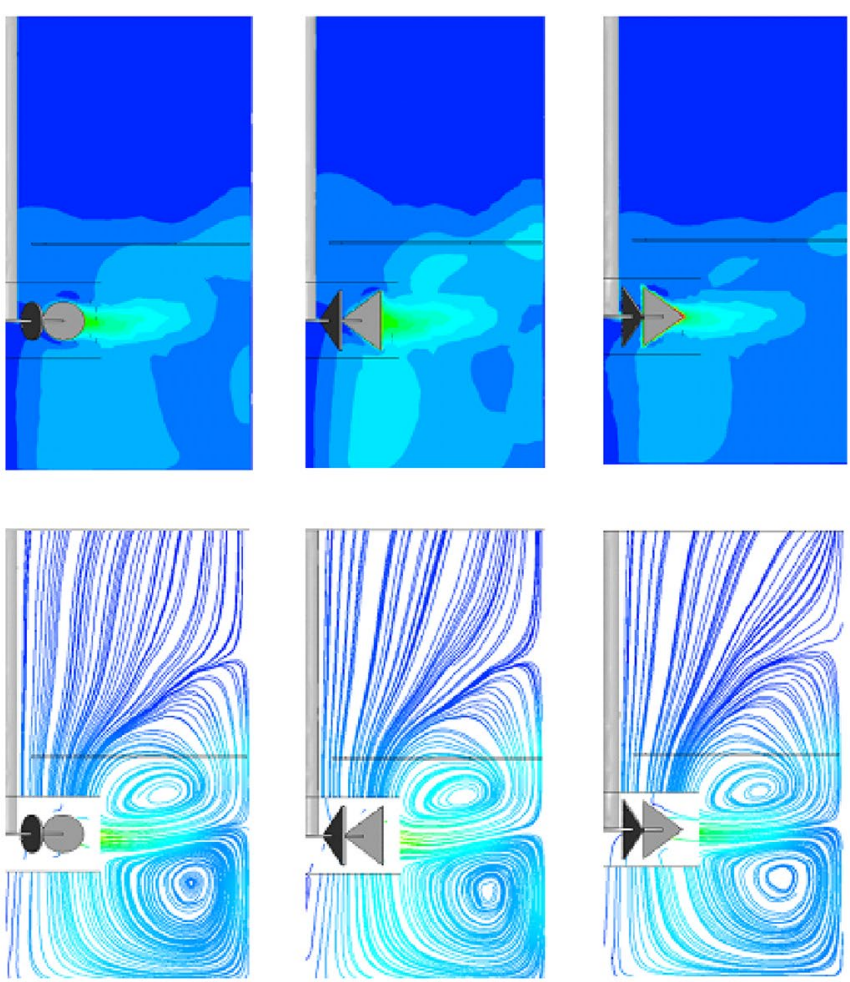

CBT

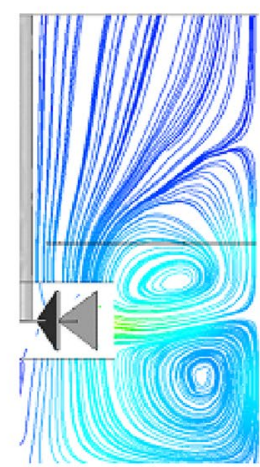

DTBT

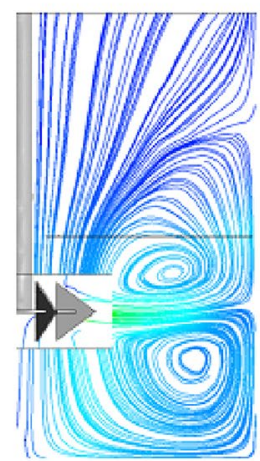

CTBT

Figure 21 Flow fields for different agitator's types of baffled tanks with CHCB for an angle $20^{\circ}, R e=4 \times 10^{4}$

DTBT and low intensity area of CTBT especially above the turbine. The streamlines are almost similar to the four agitator's types, it is noted that there is a decrease in the size of the large vortex compared to tanks with vertical baffles. These results indicate that $\mathrm{CHCB}$ at an angle of $20^{\circ}$ affects the flow field.

Axial and radial velocities for different agitator's types along the vessel radius, at $R^{\prime \prime}=0.216$ and Reynolds number $R e=4 \times 10^{4}$ are presented in Figure 22. We can note that the profiles of axial speed are almost identical for the agitators (DTBT, RT and CBT) with maximal value about
0.035 and 0.043 in the upper and the under of turbine for agitator DTBT and 0.015 in the free face of the liquid. The profiles of radial speed are similar to light variation, we see a maximal value of 0.15 on the edge of the blades and minimal about 0.05 under the blades for agitators CBT and DTBT, in a free face a null value can see.

The vortex size and power number are shown in Table 4 in a cylindrical vessel equipped with different agitator's types with $\mathrm{CHCB}$ s with an angle of $20^{\circ}$. Our numerical results were compared with the work of Ref. [37], we 

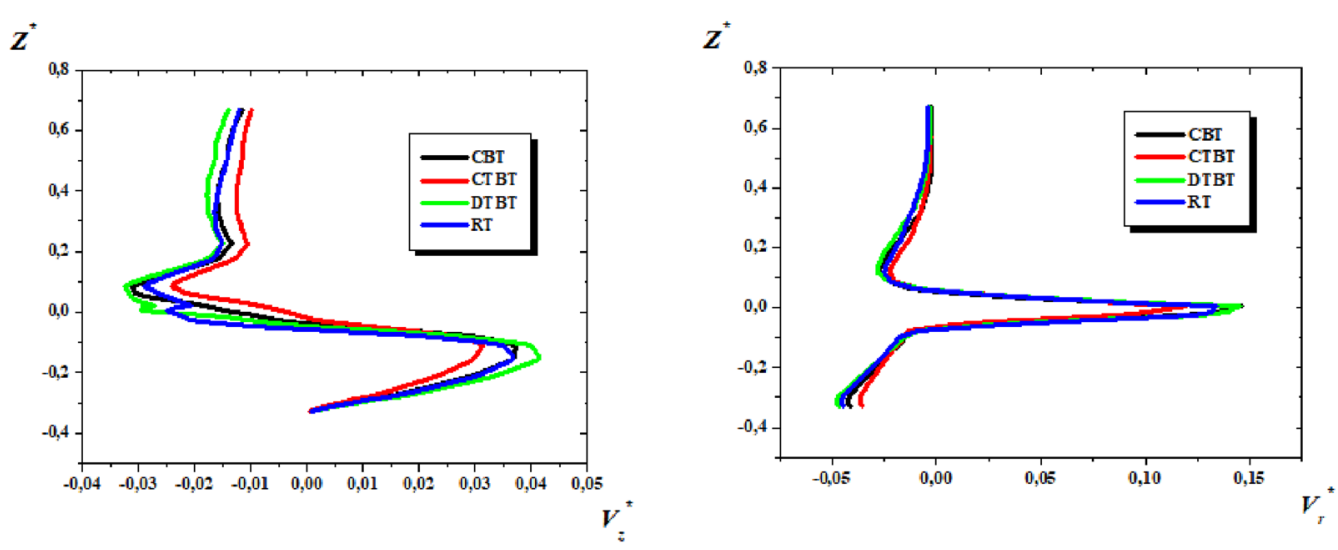

Figure 22 Axial and radial velocities for different agitator's types along the vessel radius, at $R^{*}=0.216, R e=4 \times 10^{4}$

Table 4 Vortex size \& power number for different agitator's types of tanks with CHCB

\begin{tabular}{llllll}
\hline & RT & CBT & DTBT & CTBT & $\begin{array}{l}\text { Ref. } \\
\text { [33] }\end{array}$ \\
\hline Vortex size & 0.381 & 0.383 & 0.371 & 0.398 & 0.382 \\
$N_{P}$ & 3.66 & 3.39 & 4.20 & 2.59 & 3.64 \\
\hline
\end{tabular}

found similar results concerning the vortex size of the different agitator's types and power number slightly varied, and we also noticed a significant decrease in power number of the CTBT agitator.

\subsection{Effect of the Impeller Clearance Ratio (c/D)}

In a standard tank, the height of the liquid is equal to the tank diameter. The impeller is positioned at a distance $\mathrm{c}$ generally measured from lower impeller edge to the vessel bottom; to know the influence of impeller clearance on the hydrodynamic structure, four cases of $c / D$ ratios are tested $(c / D=0.17,0.33,0.5$ and 0.67$)$ for cylindrical vessels equipped with four agitator's types (RT, CBT, DTBT, CTBT).

The evolution of the vector speed in the horizontal plane of the tank with $\mathrm{CHCB}$ with an angle $20^{\circ}$ and for the four agitators with four impeller clearance ratio $c / D$ with Reynolds number $R e=4 \times 10^{4}$ are represented in Figure 23. We can observe that the intensity of the vector speed is higher around the turbines and important in the medium and on the wall of the tanks for the four agitators with ratio $c / D=0.33$ and low intensity for the ratio $c / D=0.17,0.5$ and smaller for $c / D=0.67$, one can as see, as the direction of the vector speed around the turbines and in the middle of the tanks is different. It is deduced that the ratio $c / D=0.33$ gives a good distribution of the vector speed. Therefore, better an agitation of the fluid.

The profiles of axial speed with various impeller clearance ratios $c / D$ for different agitator's types along the vessel radius, at $R^{\prime \prime}=0.25$ and Reynolds number $R e=4 \times 10^{4}$ are shown in Figure 24.

For ratio $c / D=0.17$, a maximum value of axial speed under the turbine reaches almost 0.055 At $Z^{*}=0.2$ then slightly decreases up to the value of 0.005 at $Z=0.2$ on top of the turbine then null to the free face of the liquid for agitators DTBT and RT, for $c / D=0.33$ the height of the vortex size varies approximately 0.03 under turbine with $V_{z}{ }_{z}=0.04$ and 0.02 upper turbine with $V_{z}^{*}=0.025$ of agitator DTBT.

For $c / D=0.5, V_{z}=0.04$ and 0.045 in the under and upper of turbine for agitators DTBT and the values of $V_{z}$ in the free face of the liquid varies between 0.015 to 0.035 for all agitators. For $c / D=0.67$ the axial speed is maximized with a value of 0.06 because the agitator is closer to the free face of the liquid for agitator DTBT and minimal approximately 0.03 at $Z^{\prime \prime}=0.2$ for agitator RT.

Figure 25 shows the variation of vortex size versus the impeller clearance ratio $(c / D=0.17,0.33,0.5$ and $0.67)$ for cylindrical vessels equipped with four agitator's types (RT, CBT, DTBT, CTBT), it can be seen that all the graphs of four agitators are identical. A maximum value of the vortex size approximately 0.98 with $c / D=0.17$ then decreases until reaching a value of 0.3 with $c / D=0.67$. Thus the size of the vortex decreases with the increase of the impeller clearance ratio $(c / D)$.

We compare and validate our numerical results with the experimental one of Ref. [38], in Figure 26 the variation of the power number $N_{P}$ versus impeller clearance 


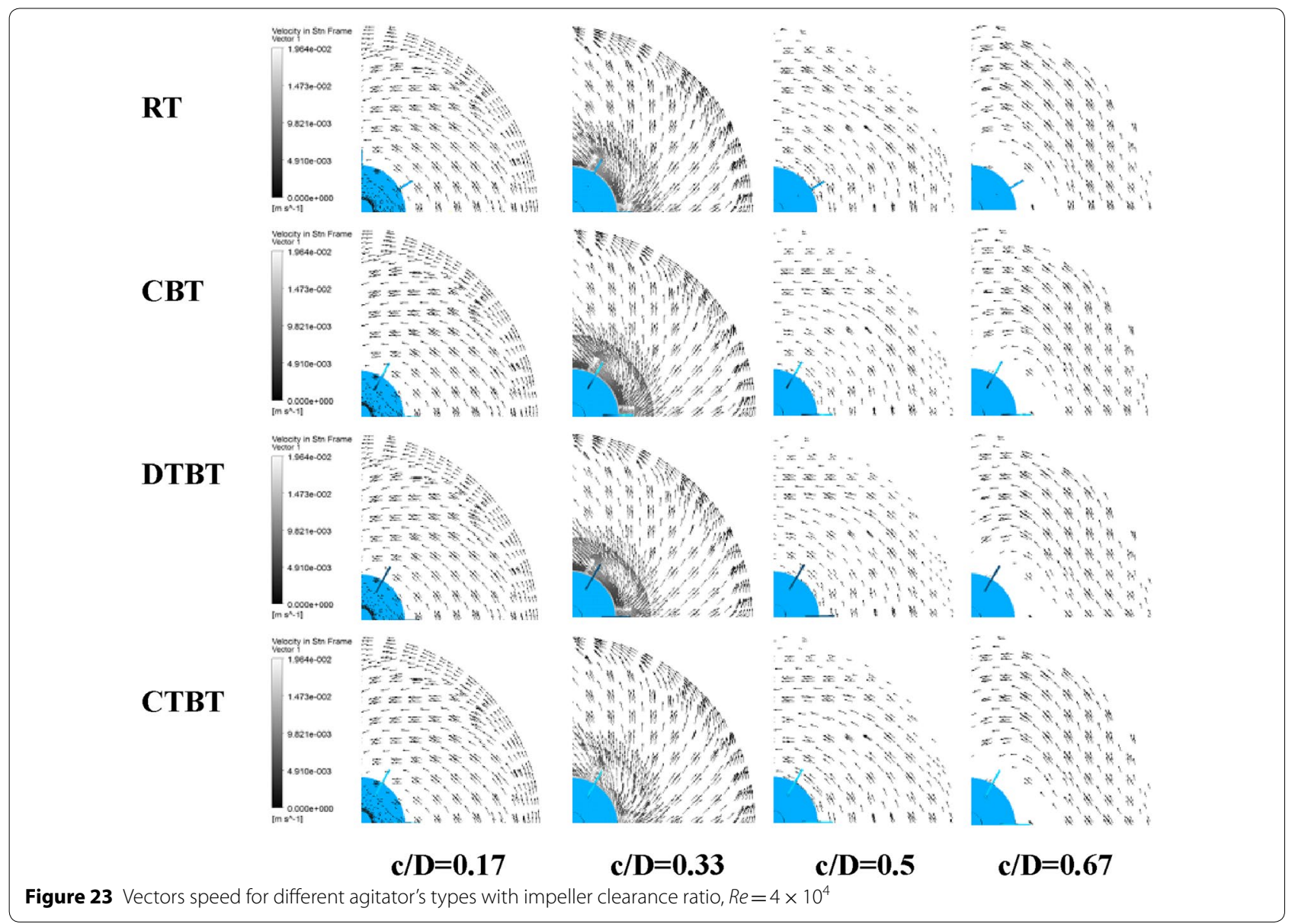

ratio $c / D$ was introduced. It can be seen that the power number increases slightly with an increase of the ratio. We deduce also, the agitator CTBT gives an important profit on the power consumption per report/ratio the others, his power number about $N_{P}=2$.

\section{Conclusions}

The geometrical shape of the baffle and the agitator is a factor very influencing on the performances of a mechanically agitated system. The baffles are essential devices in the construction of the agitated tanks.
The role of the baffles is to transform the tangential flow generated by the mobile of agitation into flow three directional, mainly axial, radial and tangential, and to also avoid the formation of the vortices on the level due to the centrifugal force. In our work, we interested to study four agitator's types (RT, CBT, DTBT, and CTBT) in tanks without and with baffles (VB and $\mathrm{CHCB}$ ) in a mode of turbulent flow.

Several parameters are tested, such as the effect of: vertical baffles baffle height, impeller angle, and circular horizontal cut baffle and impeller clearance.

In the unbaffled tank, we find that agitator CBT gives the power number similar to agitator RT and the CTBT 


$$
Z^{*}
$$

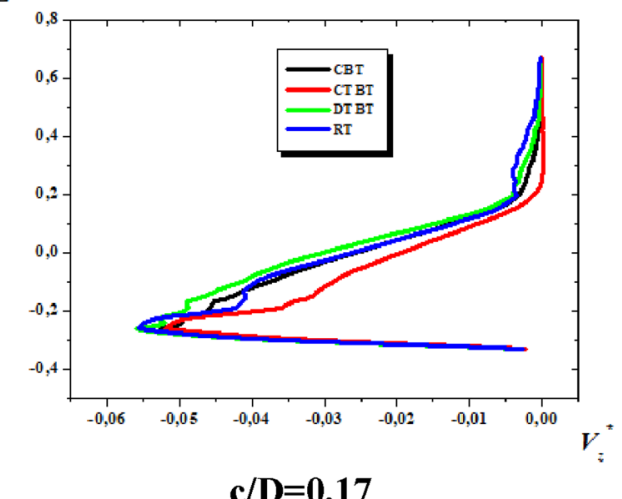

$\mathrm{c} / \mathrm{D}=\mathbf{0 . 1 7}$

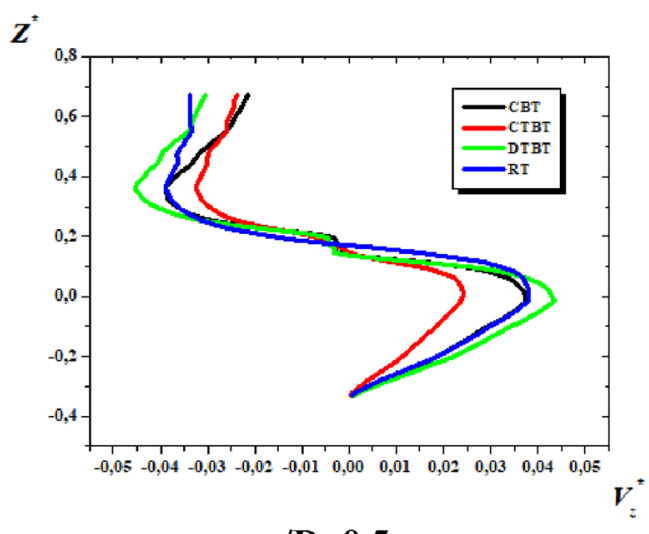

$\mathbf{c} / \mathbf{D}=\mathbf{0 . 5}$

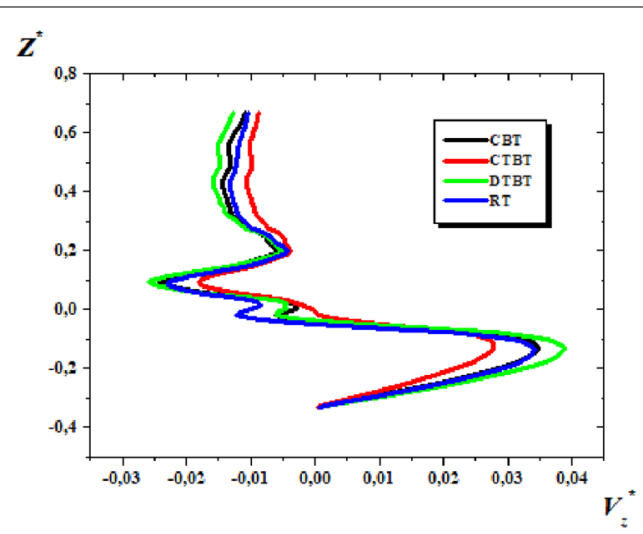

$\mathbf{c} / \mathrm{D}=\mathbf{0 . 3 3}$

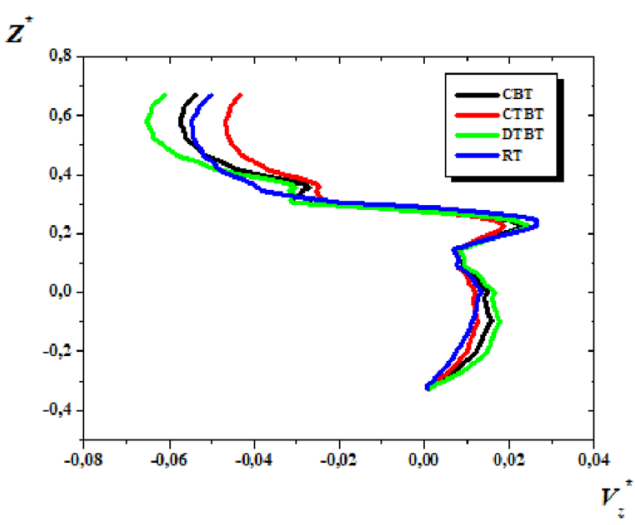

$\mathbf{c} / \mathbf{D}=\mathbf{0 . 6 7}$

Figure 24 Axial velocities for different agitator's types with impeller clearances along the vessel radius, at $R^{*}=0.25$ and $R e=4 \times 10^{4}$

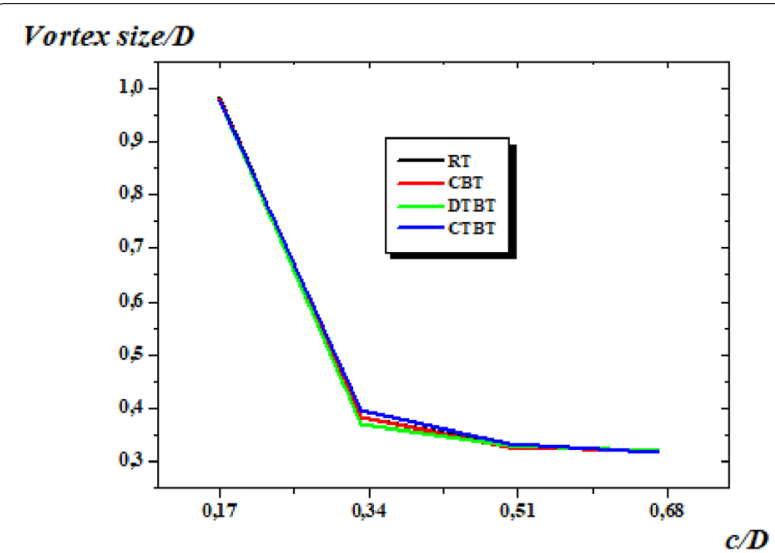

Figure $\mathbf{2 5}$ Vortex size versus the impeller clearance ratio for different agitator's types, $\operatorname{Re}=4 \times 10^{4}$

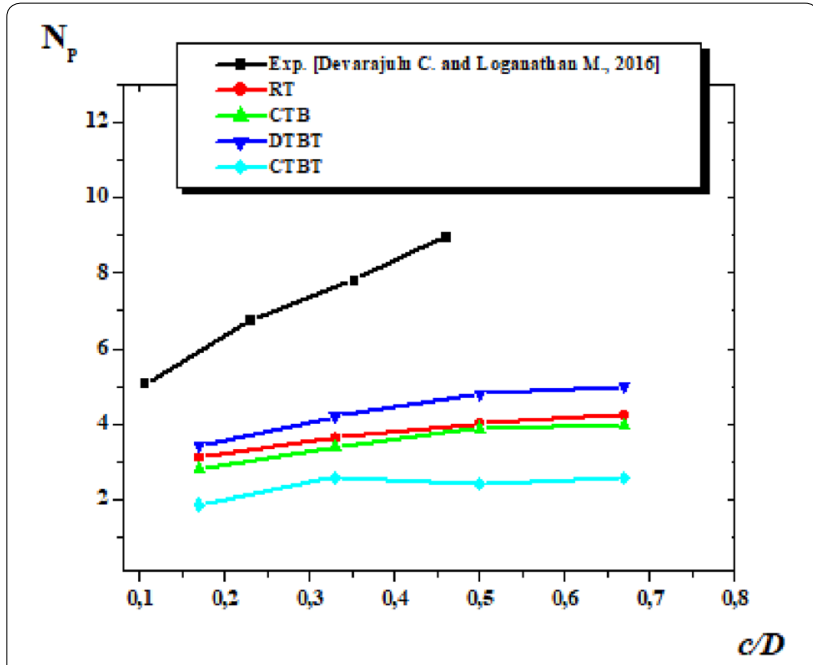

Figure 26 Power number according the impeller clearance ratio for different agitator's types, $R e=4 \times 10^{4}$ 
stirrer reduces the power consumption about $43.83 \%$ in the baffled tank. We can deduce that a reduction of the vortex size of agitators CBT, DTBT and CTBT reduced by comparison to RT with the increase baffle height.

The agitator DTBT give a good reduction of the vortex size of the impeller angles by report/ratio the other agitators.

We compare and validate our numerical results with the experimental one of Ref. [38], we deduce that the agitator CTBT gives an important profit on the power consumption per report/ratio the others, his power number about $N_{P}=2$.

\section{Nomenclature}

$a$ : Blade length $(\mathrm{m}) ; b$ : Blade width $(\mathrm{m}) ; B$ : Width of baffles $(\mathrm{m}) ; c$ : Impeller ofbottomed clearance $(m) ; C$ : Torque (N.m); $d$ : Impeller diameter $(m) ; d_{s h}$ : Shaft diameter (m); D: Tank diameter (m); e: Disc thickness (m); $g$ : Disc diameter $(m)$; $H$ : Vessel tank height $(m) ; N$ : Impeller rotational speed $\left(s^{-1}\right) ; N_{p}$ : Power number (dimensionless); P: Power (W); R: Radial coordinates (m); Re: Reynolds number (dimensionless); $V_{z}$ : Axial velocity $(\mathrm{m} / \mathrm{s}) ; V_{\theta}$ : Tangential velocity $(\mathrm{m} / \mathrm{s}) ; V_{r}$ : Radial velocity $(\mathrm{m} / \mathrm{s}) ; W$ : Baffle length $(\mathrm{m})$

\section{Greek Letters}

$\rho$ : Fluid density $\left(\mathrm{kg} / \mathrm{m}^{3}\right) ; \mu$ : Viscosity (Pa.s); $\theta$ : Angular coordinate $\left(^{\circ}\right)$; $\omega$ : Angular velocity ( $\mathrm{rad} / \mathrm{s})$.

\section{Subscripts}

CFD: Computational fluid dynamic; LDA: Laser eddy anemometry; LES: Large eddy simulation; RT: Rushton turbine; CBT: Circular blades turbine; DTBT: Diverging triangular blades turbine; CTBT: Converging triangular blades turbine; CHCB: Circular horizontal cut baffle; MRF: Multiple reference frame; RRF: Rotating reference frame; $V B$ : Vertical baffles.

\section{Authors' Contributions}

MF designed, validated and carried out the numerical simulation, writing of the manuscript, MB verified and analyzed the numerical results, worked out almost all of the technical details. All authors discussed the results and commented on the manuscript.

\section{Authors' Information}

Mohammed Foukrach (1982) is an Algerian born, PhD candidate at University of Sciences and Technology of Oran Mohamed Boudhief (USTO-MB), Oran, Algeria. His research interests include agitation system and numerical simulation.

Mohamed Bouzit is an Algerian Professor at Mechanical Faculty of Engineering, University of Sciences and Technology of Oran Mohamed Boudhief (USTO-MB), Oran, Algeria. He received his PhD degree from USTU-MB, Oran, Algeria, in 2011. His Area of research includes fluid flows, numerical simulation.

Houari Ameur (1982) is an Algerian assistant Professor at University Center of Naâma (Ctr Univ Naâma), Algeria. His research interests include CFD simulation, mixing and non-Newtonian fluid flows.

Youcef Kamla (1983) is an Algerian assistant Professor at University Hassiba Ben Bouali of Chlef (UHBC) Ouled Fares, Chlef, Algeria. His works actually on mixing, stirred tanks, heat transfer in static mixer.

\section{Funding}

No applicable.

\section{Competing Interests}

The authors declare no competing financial interests.

\section{Author Details}

${ }^{1}$ Mechanical Faculty of Engineering, University of Sciences and Technology of Oran Mohamed Boudhief (USTO-MB), 1505 El M'naouar, Oran, Algeria.

${ }^{2}$ Institute of Science and Technology, University Center of Naâma (Ctr Univ Naâma), BP 66, 45000 Naâma, Algeria. ${ }^{3}$ Faculty of Technology, University Hassiba Ben Bouali of Chlef (UHBC) Ouled Fares, Chlef, Algeria.
Received: 8 July 2019 Revised: 10 April 2020 Accepted: 19 April 2020 Published online: 01 May 2020

\section{References}

[1] A K Sahu, P Kumar, A W Patwardhan, et al. CFD modeling and mixing in stirred tanks. Chem. Engng. Sci., 1999, 54(13-14): 2285-2293. https://doi. org/10.1016/S0009-2509(98)00334-0.

[2] Bart C H Venneker, Jos J Derksen, Harry E A Van den Akker. Turbulent flow of shear-thinning liquids in stirred tanks - The effects of Reynolds number and flow index. Chemical Engineering Research and Design, 2010, 88(7): 827-843. https://doi.org/10.1016/j.cherd.2010.01.002.

[3] W Chtourou, M Ammar, Z Driss, et al. CFD prediction of the turbulent flow generated in stirred square tank by a Rushton turbine. Energy and Power Engineering, 2014, 6(5): 95-110. http://dx.doi.org/10.4236/epe.2014.65010.

[4] H Hartmann, J J Derksen, H E A van den Akker. Mixing times in a turbulent stirred tank by means of LES. AIChE, 2006, 52(11): 3696-3706. https:// doi.org/10.1002/aic.10997.

[5] Weidong Huang, Kun Li. CFD simulation of flows in stirred tank reactors through prediction of momentum source. INTECH, 2013: 135-153. https:// doi.org/10.5772/51754.

[6] V Buwa, A Dewan, A F Nassar, F Durst. Fluid dynamics and mixing of single-phase flow in a stirred vessel with a grid disc impeller: Experimental and numerical investigations. Chemical Engineering Science, 2006, 61(9): 2815-2822. https://doi.org/10.1016/j.ces.2005.10.066.

[7] J Aubin et al. Modeling turbulent flow in stirred tanks with CFD: The influence of the modeling approach, turbulence model and numerical scheme. Exp. Therm. Fluid. Sci., 2004, 28(5): 431-445. https://doi. org/10.1016/j.expthermflusci.2003.04.001.

[8] John A McCorquodale, Siping Zhou. Effects of hydraulic and solids loading on clarifier performance. Journal of Hydraulic Research, 1993, 31(4): 461-477. https://doi.org/10.1080/00221689309498870.

[9] S Xanthos, M Gong, K Ramalingam, et al. Performance assessment of secondary settling tanks using CFD modeling. Water Research Management, 2011, 25(4): 1169-1182. https://doi.org/10.1007/s11269-010-9620-1.

[10] A Tamayol, B Firoozabadi, M A Ashjari. Hydrodynamics of secondary settling tanks and increasing their performance using baffles. ASCE Journal of Environmental Engineering, 2010, 136(1): 32-39. https://doi.org/10.1061/ (ASCE)EE.1943-7870.0000126.

[11] Abdelghani Belhanafi, Mohamed Bouzit. Numerical investigation of hydrodynamics induced by a pitched blade turbine: Effect of the shape of vessel base. MECHANIKA, 2019, 25(5): 370-376. DOI: https://doi. org/10.5755/j01.mech.25.5.23015.

[12] Marta Major-Godlewska, Joanna Karcz. An effect of the tubular baffles configuration in an agitated vessel with a high-speed impeller on the power consumption. Chemical Papers, 2018, 72: 2933-2943. https://doi. org/10.1007/s11696-018-0533-4.

[13] Gregory Cartland Glover, John Fitzpatrick. Modelling vortex formation in unbaffled stirred tank reactors. Chemical Engineering Journal, 2013, 127 : 11-22. DOI: https://doi.org/10.1016/j.cej.2006.09.019.

[14] Marta Major-Godlewska, Joanna Karcz. Power consumption for an agitated vessel equipped with pitched blade turbine and short baffles. Chem Zvesti, 2018, 72(5): 1081-1088. DOI: 10.1007/s11696-017-0346-x.

[15] A Iranshahia, C Devalsa, M Henichea, et al. Hydrodynamics characterization of the Maxblend impeller. Chemical Engineering Science, 2007, 62(14): 3641-3653. https://doi.org/10.1016/j.ces.2007.03.031.

[16] Houari Ameur. Agitation of yield stress fluids in different vessel shapes. Engineering Science and Technology an International Journal, 2016, 19 (1): 189-196. https://doi.org/10.1016/j.jestch.2015.06.007.

[17] Y Kamla, et al. CFD study of the effect of baffles on the energy consumption and the flow structure in a vessel stirred by a Rushton turbine. MECHANIKA, 2016, 22(3): 190-197. DOI: https://doi.org/10.5755/j01. mech.22.3.12663.

[18] S Youcefi, M Bouzit, H Ameur, et al. Effect of some design parameters on the flow fields and power consumption in a vessel stirred by a Rushton turbine. Chem. Process Eng., 2013, 34(2): 293-307. https://doi.org/10.2478/ cpe-2013-0024.

[19] Youcef Kamla, et al. Effect of the inclination of baffles on the power consumption and fluid flows in a vessel stirred by a Rushton turbine. 
Chin. J. Mech. Eng., 2017, 30(4): 1008-1016. https://doi.org/10.1007/s1003 3-017-0158-5.

[20] Houari Ameur, et al. Numerical study of fluid flow and power consumption in a stirred vessel with a Scaba 6SRGT impeller. Chemical and Process Engineering, 2011, 32(4): 351-366. https://doi.org/10.2478/v1017 6-011-0028-0.

[21] Jing Zhao, Zhengming Gao, Yuyun Bao. Effects of the blade shape on the trailing vortices in liquid flow generated by disc turbines. Chinese Journal of Chemical Engineering, 2011, 19(2): 232-242. https://doi.org/10.1016/ S1004-9541(11)60160-2.

[22] J Karcz, M Major. An effect of a baffle length on the power consumption in an agitated vessel. Chem. Eng. Process, 1998, 37: 249-256. https://doi. org/10.1016/s0255-2701(98)00033-6.

[23] Houari Ameur, Mohamed Bouzi. Numerical investigation of flow induced by a disc turbine inunbaffled stirred tank. Acta Scientiarum. Technology, 2013, 35(3): 469-476. https://doi.org/10.4025/actascitechnol.v35i3.15554.

[24] Harshal Patil, et al. CFD simulation model for mixing tank using multiple reference frame (MRF) impeller rotation. ISH Journal of Hydraulic Engineering, 2018: 1-10. https://doi.org/10.1080/09715010.2018.1535921.

[25] Pan Zhang, et al. Mixing characteristics in a vessel equipped with cylindrical stirrer. Results in Physics, 2018, 10: 699-705. https://doi.org/10.1016/j. rinp.2018.07.024.

[26] Xianhua Li, et al. Development of a computational fluid dynamics model for scaling-up Ambr bioreactors. Biotechnology and Bioprocess Engineering, 2018, 23(6): 710-725.https://doi.org/10.1007/s12257-018-0063-5.

[27] W Huang, et al. Computational fluid dynamics simulation of flows in an oxidation ditch driven by a new surface aerator. Environ Eng. Sci., 2013, 30(11): 663-671. DOI: 10.1089/ees.2012.0313.

[28] Sanaie-Moghadam Maryam, et al. Determination of stationary region boundary in multiple reference frames method in a mixing system agitated by Helical Ribbon Impeller using CFD. J. Hea. Mas. Tran. Reas., 2015, 2(1):31-37. https://doi.org/10.22075/jhmtr.2015.337.

[29] W Chtourou, et al. Effect of the turbulence models on Rushton turbine generated flow in a stirred vessel. Cent. Eur. J. Eng., 2011, 1(4): 380-389. DOI: https://doi.org/10.2478/s13531-011-0039-0.
[30] Jyeshtharaj B Josh, et al. CFD simulation of stirred tanks: Comparison of turbulence models. Part l: Radial flow impellers. The Canadian Journal of Chemical Engineering, 2011, 89(1): 23-82. https://doi.org/10.1002/ cjce.20446.

[31] Binxin Wu. CFD investigation of turbulence models for mechanical agitation of non-Newtonian fluids in anaerobic digesters. Water Research, 2011, 45(5): 2082-2094. https://doi.org/10.1016/j.watres.2010.12.020.

[32] Víctor X Mendoza-Escamilla, et al. Assessment of $k-\varepsilon$ models using tetrahedral grids to describe the turbulent flow field of a PBT impeller and validation through the PIV technique. Chin. J. Chem. Eng., 2018, 26 (5): 942-956. https://doi.org/10.1016/j.cjche.2018.02.012.

[33] L Oshinowo, Z Jaworski, K N Dyster, et al. Predicting the tangential velocity field in stirred tanks using the multiple reference frames (MRF) model with validation by LDA measurements. Proceedings of the 10th European Conference on Mixing, Delft, Netherlands, July 2-5, 2000: 281-288. https:// doi.org/10.1016/B978-044450476-0/50036-4.

[34] D P Karadimou, et al. Mathematical modeling and numerical simulation of two-phase gas-liquid flows in stirred-tank reactors. Journal of King Saud University -Science, 2019, 31(1): 33-41. https://doi.org/10.1016/j.jksus 2017.05.015.

[35] Li Jiajia, et al. CFD simulation of an unbaffled stirred tank reactor driven by a magnetic rod: assessment of turbulence models. Water Sci. Technol., 2015, 72(8): 1308-1318. https://doi.org/10.2166/wst.2015.314.

[36] L Pakzal, F Ein-Mozaffari, P Chan. Using computational fluid dynamics modeling to study the mixing of pseudoplastic fluid with a Scaba 6SRGT impeller. Chem. Eng. Pro., 2007, 47(12): 2218-2227. https://doi. org/10.1016/j.cep.2007.12.003.

[37] M Foukrach, et al. Influence of the vessel shape on the performance of a mechanically agitated system. Chemical Papers, 2019, 73(2): 469-480. https://doi.org/10.1007/s11696-018-0606-4.

[38] C Devarajulu, M Loganathan. Effect of impeller clearance and liquid level on critical impeller speed in an agitated vessel using different axial and radial impellers. J. Appl. Fluid Mech., 2016, 9 (6): 2753-2761. https://doi. org/10.29252/jafm.09.06.24824.

\section{Submit your manuscript to a SpringerOpen ${ }^{\circ}$ journal and benefit from:}

- Convenient online submission

- Rigorous peer review

- Open access: articles freely available online

- High visibility within the field

- Retaining the copyright to your article

Submit your next manuscript at $\boldsymbol{\nabla}$ springeropen.com 